\title{
Cirilo Villaverde oder der Roman eines Jahrhunderts
}

Señá Chepa erzählt ihrer Enkelin ein Märchen: Es war einmal, da hörte die kleine Narcisa eine Geige spielen und lief, während ihre Großmutter betete, hinauf zur Loma del Ângel zum Tanz. Ein hübscher junger Mann bot ihr an, sie zu begleiten und das Mädchen willigte ein. Doch während sie so gingen, wurde der junge Mann plötzlich kohlrabenschwarz, zwei Hörner wuchsen aus seinem Schädel, ein langer buschiger Schwanz wurde sichtbar, Feuer drang aus seinem Maul: Narcisa erkannte in dem hübschen jungen Mann den Teufel. Doch es war zu spät, alle Gegenwehr vergeblich, der Teufel hatte sie gepackt:

\begin{abstract}
Dann stieß Narcisa einen Schrei des Schreckens aus und versuchte sich loszureißen, aber die schwarze Figur bohrte ihre Fingernägel in ihre Kehle, um sie am Schreien zu hindern, packte sie und stieg mit ihr auf den Turm des Engels, der, wie ihr bemerkt haben werdet, kein Kreuz trägt, und von dort aus warf er sie in einen tiefen, tiefen Brunnen, der sich öffnete und, nachdem er sie verschluckt, im Handumdrehen wieder schloss. Das also ist es, mein Töchterchen, was mit den Mädchen passiert, die auf die Ratschläge der Älteren nicht hören. ${ }^{1}$
\end{abstract}

Dieser „cuento de cuentos“ ${ }^{2}$ der Großmutter Chepa im dritten Kapitel des ersten Teils von Villaverdes Cecilia Valdés o La Loma del Ángel verfehlt, wie der Erzähler kommentiert und die Leserinnen und Leser später verstehen, gänzlich seinen moralischen Effekt bei seinem ,Zielpublikum‘. Das „Märchen von Märchen“ entwirft in nuce das spätere Schicksal des Mädchens: den Versuch der jungen Mulattin Cecilia, ihre Schönheit auszuspielen, einen Weißen zu heiraten und damit den ersehnten gesellschaftlichen Aufstieg in einer rassistischen Gesellschaft zu bewerkstelligen. Der Versuch wird scheitern, Cecilia fällt ins Nichts zurück. Das Märchen ist somit eine ganz wörtlich zu nehmende Mise en abyme, eine Art Fraktal der folgenden, hier in ihren Grundzügen skizzierten Romanhandlung. Was aber macht die gesellschaftliche Bedeutung dieses Romans von Cirilo Villaverde aus? Und wieso konnte dieser Erzähltext und seine Protagonistin zum Inbegriff des kubanischen 19. Jahrhunderts und zu jener Figur avancieren, die wie keine andere für die kollektive Identität der Insel Kuba steht?

1 Villaverde, Cirilo: Cecilia Valdés o La Loma del Ángel. La Habana: Editorial Arte y Literatura 1977, S. 77.

2 Ebda., S. 76.

2 Open Access. (c) 2021 Ottmar Ette, publiziert von De Gruyter. (c))BY-NC-ND Dieses Werk ist lizensiert unter einer Creative Commons Namensnennung - Nicht-kommerziell - Keine Bearbeitung 4.0 International Lizenz. https://doi.org/10.1515/9783110703443-024 


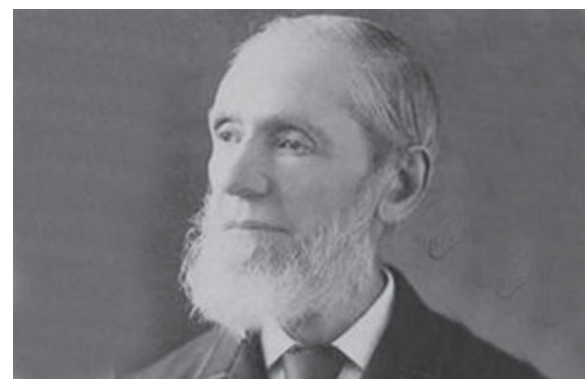

Abb. 56: Cirilo Villaverde (San Diego de Núñez, Kuba, 1812 - New York City, 1894).

Dass die Wirkung des Märchens bei der Enkelin verpufft, hat die alte Chepa allein sich selbst zuzuschreiben. Denn unmittelbar zuvor hatte sie - eine herrliche Zukunft prophezeiend - einmal mehr Illusionen bei der jungen Mulattin geweckt, sei sie doch fast weiß, „casi blanca“, und dürfe zurecht auf die Heirat mit einem Weißen hoffen: „Denn Dein Vater ist ein weißer Herr, und eines Tages wirst $\mathrm{Du}$ reich sein und in einer Kutsche daherkommen.." Die Großmutter hat die Erwartungen ihrer hübschen Enkelin mithin selbst genährt und Hoffnungen geweckt, ihre physische Schönheit in klingende Münze zu verwandeln sowie in die reiche weiße Gesellschaft der Zuckerrohrinsel aufzusteigen.

Bereits die Stellung des Märchens zwischen dem zufälligen Besuch der kleinen Cecilia bei den reichen Gamboas im zweiten Kapitel des ersten Teils und dem spektakulären Auftritt der von allen als „Virgencita de bronce“, als bronzefarbene Jungfrau gepriesenen Schönheit Jahre später auf einem Ball der freien Mulatten und Schwarzen in Havanna weist auf die Bedeutung dieser Schlüsselszene deutlich hin. Elemente aus der Erzählung der Großmutter finden sich denn auch am Rande dieses „Baile de cuna“ wieder; so der Brunnen ${ }^{4}$ des Märchens wie die dort auftauchende luxuriöse Kutsche, ${ }^{5}$ in der Cecilia später vorfährt. Cirilo Villaverde hat die literarische Grundstruktur seines Erzähltextes sorgsam aufgebaut.

Diese reich ausgestattete Kutsche gehört einem wohlhabenden Weißen, Leonardo, Sohn des aus Andalusien stammenden, zu Geld und Ansehen gekommenen Sklavenhändlers Gamboa, der kräftig am Aufstieg Kubas zu der Zuckerinsel in der Karibik verdient. Denn die ökonomische Verwandlung Kubas war erst nach der erfolgreichen Haitianischen Revolution mit der verstärkten Einfuhr schwarzer Sklaven möglich geworden. Leonardo war unmittelbar vor Chepillas Märchen

3 Ebda., S. 74: „Tu padre es un caballero blanco, y algún día has de ser rica y andar en carruaje.“

4 Ebda., S. 84.

5 Ebda., S. 91. 
zum ersten Male in Cecilias Worten aufgetaucht; denn schon als Junge verhielt er sich nicht anders als im späteren Verlauf des Romans: „Immer, wenn er mich sieht, will er mich fangen, er läuft hinter mir her und kennt meinen Namen.“6 Leonardo ist von Kindesbeinen an ganz in das hübsche mulattische Mädchen verknallt und betrachtet sie als sein Spielzeug.

Doch Leonardos Vater - dies wissen im Gegensatz zu Chepa weder Cecilia noch ihr junger Verfolger - ist auch ihr Vater. Die Leserschaft erfährt, wie der mit einer reichen Kreolin verheiratete Spanier seiner Geliebten, der Mulattin Charo Alarcón, ihr Kind Cecilia wegnahm, um es ins Waisenhaus zu bringen, wo man dem Säugling, wie damals auf Kuba üblich, den Nachnamen Valdés gab. Bevor die Mutter darob dem Wahnsinn verfiel, verfluchte sie ihren ehemaligen Liebhaber und wünschte ihn in die Hölle. ${ }^{7}$

Ein Fluch, der offensichtlich seine Wirkung zeitigt: Schon zwei Seiten später erschrickt Cecilias schwarze Urgroßmutter vor Gamboa wie vor dem Leibhaftigen. ${ }^{8}$ Die Großmutter - bemüht, ihre Enkelin von ihrem Vater fern $\mathrm{zu}$ halten warnt sie vor Gamboa wie vor dem Teufel, ${ }^{9}$ aber auch vor dessen Sohn Leonardo, auf den sich dieser Fluch übertragen zu haben scheint: „der fiel dem Barabbas höchstselbst aus den Klauen. “10 Doch einmal mehr scheitert Chepillas Ansinnen: Der Inzest zwischen den beiden unwissenden Geschwistern kündigt sich schon an. Denn es ist Leonardo, der - schwarzer Verführer und reicher Weißer in einer Person - Cecilia zum Tanze führt und schließlich auch verführen wird. Das Thema des Inzests ist hierbei eines, das Cirilo Villaverde den an Inzesten reichen zeitgenössischen Feuilletonromanen entnahm.

Die verteufelte Teufelei bleibt freilich nicht auf die zentrale Liebesbeziehung zwischen Cecilia und Leonardo beschränkt. Ihre Funktion ist weitaus umfassender und komplexer. Im Märchen der Großmutter, selbst Tochter einer schwarzen Mutter und eines weißen Vaters, ist der Leibhaftige wie wir schon wissen, so schwarz wie Kohle: „prieto, muy prieto, como carbón. "11 Auch hieran wird die Orientierung der mulattischen Stadtbevölkerung an den rassistischen und rasseorientierten Vorstellungen der weißen Kolonialherren und Kreolen deutlich; eine Orientierung, welche die Großmutter an ihre Enkelin weitergibt. Die immer selbe Geschichte pflanzt sich fort!

\footnotetext{
6 Ebda., S. 74: „Siempre que me ve me quiere coger, me corre detrás y sabe mi nombre ...“

7 Ebda., S. 53.

8 Ebda., S. 55.

9 Ebda., S. 73.

10 Ebda., S. 74: „se le cayó de las uñas al mismo Barrabás.“

11 Ebda., S. 77.
} 
Im Romangeschehen selbst ist der Teufel jedoch nicht schwarz. Die Assoziierung von Vater und Sohn Gamboa, von Weißen also, mit dem Teufel - etwa durch Cecilias Freundin Nemesia ${ }^{12}$ - weist damit auf den zweiten thematischen Hauptstrang des Romans. Denn damit ist dessen abolitionistische Stoßrichtung angesprochen. Der Kreole, also der auf Kuba geborene Weiße Leonardo, der mit der nächtlichen Auspeitschung seines Sklaven die geheiligte Nachtruhe seiner Eltern stört, wird von seinem eigenen Vater als „muchacho de Barrabás“, als Junge von Barabbas apostrophiert. Und sein Vater, der Spanier Gamboa selbst, zerstreut die selten einmal aufkommenden Skrupel seiner Frau angesichts der zynischen Brutalität des Sklavenschinders mit dem Hinweis, sie könne ihre Gewissenszweifel, ja ihre Schuld ruhig auf ihn abwälzen: „Du weißt ja, dass der Teufel sie übernimmt."13 Immer wieder also ist Satan im Spiel - nur dass die wahren Teufel eben nicht schwarz, sondern die Weißen, die Sklavenhalter sind.

Angesichts solcher Äußerungen erscheint es nur logisch, wenn wenige Seiten danach ein geschundener Sklave als „Christus aus Ebenholz am Kreuze“, als „Jesucristo de ébano en la cruz“14 erscheint oder die Opfer der weißen Teufel, die Sklaven an der Dampfmaschine des „Ingenio“, mit der Darstellung der Seelen im Fegefeuer in Verbindung gebracht werden. ${ }^{15}$ Kein Zweifel: Cecilia Valdés gehört in die Reihe abolitionistischer Romane, die in Kuba mit Gertrudis Gómez de Avellanedas in spanischer Sprache erstveröffentlichten und bereits besprochenen Roman Sab im Jahre 1841 begann und mit El negro Francisco (1873) von Antonio Zambrana sowie vor allem mit Francisco (1880) von Anselmo Suárez y Romero ebendort fortgesetzt wurde. Es sind Romane, welche mit literarischen Mitteln die Abschaffung der Sklaverei forderten und wie Sab entweder lange Zeit oder erst kurz vor deren Abschaffung auf Kuba erschienen.

So durchgängig der Rückgriff auf christliche Vorstellungen im gesamten Roman auch sein mag: Er scheint den bisherigen Interpreten wohl eher entgangen zu sein. Dies dürfte nicht allein in der Konventionalität eines derartigen Musters begründet liegen, sondern vor allem in der Tatsache, dass das Bild, welches der kubanische Romancier von seinen Figuren entwirft, so simpel nicht war, wie es die schwarz-weißen Zuweisungen vielleicht vermuten ließen. Denn die Protagonisten sind nur Figuren in einem Spiel des ,Teufels‘, das auf mehreren Ebenen innerhalb einer rassistischen, kolonialistischen und paternalistischen Gesellschaft stattfindet.

12 Ebda., S. 278.

13 Ebda., S. 532: „Tú sabes que el diablo las carga.“

14 Ebda., S. 533.

15 Ebda., S. 573. 
Leonardo ist wie sein Vater, der sich um den Unterhalt seiner unehelichen Tochter Cecilia und deren Großmutter kümmert, sehr wohl zu menschlichen Regungen fähig. Cecilia ihrerseits ist keineswegs das unschuldige Opfer des Teufels, sondern trägt selbst wesentlich zu ihrem Verderben bei, ist sie in ihrem unbedingten Aufstiegswillen doch ebenso sehr von rassistischen Vorstellungen durchdrungen wie die Sklavenhändlerfamilie Gamboa. Cirilo Villaverdes allwissender Erzähler zeigt, wie sehr alle in einer von der Arbeit der Sklaven lebenden Gesellschaft vom Rassismus durchdrungen und zerfressen sind. Daran wird deutlich, dass das Leben in einer Sklavenhaltergesellschaft die Vorstellungen aller Bewohner korrumpiert, wie die am sympathischsten dargestellte Figur der Isabel Ilincheta erkennt.

Es ist daher aus Villaverdes Sicht nicht mehr als konsequent, wenn auch die schöne Mulattin Cecilia, die schon als junges Mädchen nur oberflächlich dem Typus der „Jungfrauen der berühmtesten Maler“16 entsprach - ließ ihr Mund doch schon damals auf „mehr Wollust als Charakterstärke“17 schließen -, ihrerseits von Leonardo Gamboa zumindest als „Teufelchen in weiblicher Gestalt“18 demaskiert wird. Als Engel innerhalb der spanischen Kolonialgesellschaft erscheint allein die humanitäre und tugendsame Isabel. Für sie ist freilich kein Platz auf dem Schachbrett des Teufels, der kubanischen Sklavenhaltergesellschaft vorgesehen: Sie wird ihr Lebensende folgerichtig nicht auf ihrer Kaffeeplantage, sondern wie die gute Teresa in Tulas Sab im Kloster beschließen. Cecilia Valdés aber liegt solches fern: Sie gehört zu dieser Gesellschaft und spielt die ihr zugewiesene Rolle perfekt. Cecilia ist ebenso sehr sinnliche, betörende Mulattin wie männermordende Femme fatale, welche längst im Feuilletonroman des 19. Jahrhunderts ihren Einzug gehalten hatte. Und noch mehr: Sie wird anders als Sab im gleichnamigen Roman der Avellaneda zur mulattischen Verkörperung Kubas.

Um dies nachzuvollziehen, sind bei unserer Annäherung an diesen in gewisser Weise identitätsbildenden Erzähltext auf dem Weg zur kubanischen Nationenbildung mehrere Analyseschritte notwendig. ${ }^{19}$ In seinem bemerkenswerten

16 Ebda., S. 57: „vírgenes de los más célebres pintores.“

17 Ebda.: „más voluptuosidad que firmeza de carácter.“

18 Ebda., S. 477: „diablito en figura de mujer.“

19 Vgl. hierzu Ette, Ottmar: „El realismo, según lo entiendo“: sobre las apropiaciones de realidad en la obra de Cirilo Villaverde. In: Dill, Hans-Otto / Gründler, Carola / Gunia, Inke / Meyer-Minnemann, Klaus (Hg.): Apropiaciones de realidad en la novela hispanoamericana de los siglos XIX y XX. Frankfurt am Main - Madrid: Vervuert Verlag 1994, S. 75-89; sowie (ders.): „Cecilia Valdés“ y „Lucía Jerez“: cambios del espacio literario en dos novelas cubanas del siglo XIX. In: Letras Cubanas (La Habana) 4 (abril - junio 1987), S. 145-160. 
„Prólogo del autor“, in New York verfasst und auf den Mai des Jahres 1879 datiert, entwickelte Cirilo Villaverde die komplizierte Entstehungsgeschichte seines Romans, die er sowohl mit seiner eigenen Biographie als auch mit der politischen Entwicklung Kubas verknüpfte. Die Veröffentlichung einer Erzählung mit dem Titel Cecilia Valdés 1839 in einer kubanischen Zeitschrift und die Publikation des ersten Teils eines gleichnamigen Romans im selben Jahr in Kuba markieren den Beginn einer jahrzehntelang unterbrochenen Romangenese. Diese deutet auf die Kolonialgeschichte der Insel insgesamt, ganz wesentlich aber auch auf die fundamentale Spaltung des literarischen Feldes Kubas in einen insel- und einen exilkubanischen Teil. Zwischen der ersten Teilveröffentlichung in Kuba und der definitiven Publikation des Romans 1882 in den USA liegen mehr als vierzig Jahre. Man darf daher mit Fug und Recht behaupten, dass Cecilia Valdés o La Loma del Ángel ein Erzähltext ist, der die beiden Jahrhunderthälften kubanischer Literatur miteinander verbindet und zugleich den Roman eines ganzen Jahrhunderts darstellt, welcher beide Hälften des literarischen Feldes Kubas miteinander vermittelt. Die Entstehung von Sab fällt daher in denselben Zeitraum wie die Erstveröffentlichung der Erzählung Villaverdes und situiert sich wie diese im identischen gesellschaftlichen Umfeld.

Die Erinnerung an sein in das Blut seiner besten Söhne getauchtes Vaterland - an „la patria empapada en la sangre de sus mejores hijos“ - sei es schließlich gewesen, so Villaverde, die ihn dazu angespornt habe, „das getreue Gemälde seiner Existenz unter dem dreifachen Gesichtspunkt des Physischen, Moralischen und Gesellschaftlichen" ${ }^{20}$ doch noch im US-amerikanischen Exil abzuschließen. Genau hierin, in der Qualität des Romans als „Spiegelbild der kubanischen Gesellschaft in der ersten Hälfte des 19. Jahrhunderts“, ${ }^{21}$ erkannte man in der Folge dessen hauptsächliche Bedeutung. Dies allein hätte Cecilia Valdés aber die unbestrittene Ausnahmestellung innerhalb der kubanischen Literaturgeschichte nicht verschafft.

Sieht man von bestimmten ,Anachronismen‘ ab, auf die später noch zurückzukommen sein wird, erfasst Villaverdes Roman in seiner Diegese den Zeitraum zwischen 1812 und 1831. Der kubanische Schriftsteller entwirft dabei ein um Vollständigkeit bemühtes Bild der spanischen Kolonialgesellschaft auf Kuba. Dieses reicht vom spanischen Generalkapitän an der Spitze über spanische Geschäfts-

20 Villaverde, Cirilo: Cecilia Valdés o La Loma del Ángel, S. 28: „la fiel pintura de su existencia bajo el triple punto de vista físico, moral y social.“

21 Vgl. zum Beispiel Schnelle, Christel: Der Roman „Cecilia Valdés“ von Cirilo Villaverde, ein Spiegelbild der kubanischen Gesellschaft in der ersten Hälfte des 19. Jahrhunderts. In: Beiträge zur Romanischen Philologie (Weimar) XXII, 1 (1983), S. 21-30. 
leute, Militärs und Sklavenhändler, die kreolische Oligarchie, kleinere Beamte und Kaufleute, freie Mulatten und Schwarze bis hinunter zu den Sklaven in der Stadt und auf den Plantagen der Provinz. ${ }^{22}$ Des Weiteren tauchen „Gente de mala vida“, „Negros curros“ in der Stadt und (zumindest andeutungsweise) „Cimarrones“, entlaufene und in die Berge geflüchtete Sklaven in ihren Verstecken auf. So wird ein Querschnitt durch die kubanische Kolonialgesellschaft geboten, der jenen ähnlich ist, wie sie etwa José Joaquín Fernández de Lizardi in seinem $E l$ Periquillo Sarniento entwarf.

Über die eigenen Erfahrungen hinaus konnte Cirilo Villaverde bereits auf umfangreiche Statistiken und Untersuchungen kubanischer Autoren - unter ihnen vor allem José Antonio Saco - für sein breites Gemälde der Kolonialgesellschaft zurückgreifen. Zweifellos fußte seine Darstellung aber auch auf den Ergebnissen von Alexander von Humboldts Essai politique sur l'île de Cuba, der auf der Insel zwar rasch der Zensur anheimfiel, unter den gebildeten Kreolen in französischen Ausgaben oder spanischen Übersetzungen aber sehr wohl zirkulierte und 1856 in den USA in einer neuen, allerdings grundlegend verfälschenden Ausgabe aufgelegt worden war.

Humboldts Aussagen und Bewertungen sowie insbesondere das von ihm vorgelegte statistische Zahlenmaterial dokumentierten überdeutlich den verstärkten Sklavenimport, ungeachtet der 1817 geschlossenen Abmachungen zwischen Spanien und Großbritannien. Denn es seien zwischen 1811 und 1825 (also während des im Roman behandelten Zeitraums), „auf gesetzlichen wie ungesetzlichen Wegen“ 185.000 Sklaven nach Kuba importiert worden, wobei zwischen 1811 und 1820 allein der Zoll von Havanna 116.000 Sklaven ordnungsgemäß registriert habe. Die hierdurch nur angedeutete dramatische Entwicklung, die dem kubanischen Schriftsteller damit auch in ihrem quantitativen Ausmaß bekannt war, bildet den Hintergrund für die Ereignisse des Romans und zugleich jene argumentative Folie, auf der sich die abolitionistische Hauptthese entfalten konnte. Nach dem ,Ausfall‘ von Saint-Domingue als Zuckerlieferanten durch die Haitianische Revolution belegt dies den Aufstieg Kubas zur weltweit dominanten Zuckerinsel sowie die damit verbundenen gesellschaftlichen Entwicklungen.

Villaverdes erste literarische Bearbeitungen des Stoffes standen noch ganz in der Tradition des feuilletonistischen Romans und seiner eigenen zahlreichen Publikationen in kubanischen Blättern. Sie waren eher kostumbristische Sittenbilder im Bannkreis einer Inzestproblematik. Doch machte der Untertitel „La Loma del Ángel“ in Anspielung auf ein Stadtviertel Alt-Havannas, in dem ein großer Teil

22 Ebda., S. $23 \mathrm{ff}$. 
der Handlung und selbst das Märchen der Großmutter angesiedelt sind, unverkennbar auf die soziologische Intention des Werkes aufmerksam, welche dann in dessen definitiver Fassung zum Tragen kam. Der Stadtplan Havannas wurde zum Grundmuster von drei der vier Kapitel des kubanischen Erzähltextes.

Die Topographie der Stadt, das Kommen und Gehen der Romanfiguren, die Lage ihrer Villen, Häuschen und Hütten: All dies verweist anschaulich auf die Rassen- und Klassenschranken der kolonialen Gesellschaft, auf die angesprochene Segregation der Bevölkerung, die gerade im Gegensatz zwischen den Weißen und den ,freien Farbigen' innerhalb der Viertel der Altstadt und ihrer damals sieben Vorstädte topographisch zum Ausdruck kommt. Der geographische Raum der Stadt wird in seiner sozialen und ethnischen Hierarchie greifbar: Humboldts Statistiken wird gleichsam romaneskes Leben eingehaucht, sie verwandeln sich in die Darstellung einer gelebten und lebendigen Wirklichkeit. Die Flucht des Sklaven Dionisio aus dem Hause Gamboas, sein vergebliches Untertauchen in den Vierteln der ,freien Farbigen', aber auch die Streifzüge seiner Frau María de Regla auf der Suche nach Arbeit mögen neben den Bewegungen der Hauptfiguren hierfür als Beispiele stehen. Der Roman lässt sich als kenntnisreiche Sozialanalyse lesen.

Cirilo Villaverde verstand es geschickt, seinem Lesepublikum nicht nur einen soziologischen Schnitt durch die kubanische Stadtgesellschaft zu bieten, sondern gleichzeitig anhand der Romanereignisse des dritten Teils die Situation in der Stadt mit jener auf dem Land in Beziehung zu setzen und das Verhältnis zwischen Haussklaven und Plantagensklaven zu beleuchten. Dabei gerieten nicht nur die Unterschiede zwischen der städtischen Sklaverei und der noch unmenschlicheren Ausbeutung der Sklaven auf den Zuckerrohrplantagen, sondern auch die ökonomische Verankerung der gepflegten, an der neuesten europäischen Mode ausgerichteten Urbanität der spanischen und kreolischen Oligarchie inmitten der brutalen Explotation der versklavten Bevölkerung ins Bild. Es handelt sich um eine Situation, die Villaverde häufig durch eine Technik des Kontrastierens hervorhob. Unter anderem an dieser Technik zeigt sich die Verankerung des kubanischen Schriftstellers in einer Ästhetik der Romantik: Es sind Kontraste, welche die Romanhandlung ständig vorantreiben.

Mittels dieser Technik entwickelte Villaverde auch eine Differenzierung von ebenso landschaftlich-agrarischer Prägnanz wie sozio-politischer Bedeutung. Noch heute lassen sich wesentliche Umgestaltungen der kubanischen Gesellschaft jener Zeit erkennen und auf die veränderte Lage der Insel im 19. Jahrhundert beziehen. So schloss er seine euphorische und exotisierende Schilderung der Natur im Osten Kubas mit einem abrupten Gegensatz: 


\begin{abstract}
Es gibt keinerlei Gleichheit zwischen der Physiognomie des Landes, das man auf beiden Seiten der Berge erblickt. Im Süden erstreckt sich die Ebene mit ihren Kaffeepflanzungen, ihren Viehweiden und ihren Tabakpflanzungen, und dies zieht sich bis zum äußersten Ende der Insel hin, die freundlichste und lächelndste Landschaft, die man sich nur vorstellen kann. Im Norden hingegen bietet sich den Blicken des Reisenden auf derselben Breite ein so tiefes, raues und bedauerliches Bild, dass er ein anderes Land mit einem anderen Klima $\mathrm{zu}$ betreten vermeint. ${ }^{23}$
\end{abstract}

Die beiden Seiten der Berge, die geradezu zwei Welten voneinander trennen, erinnern - neben anderen Darstellungsmustern - an die berühmte und ebenso kontrastive Schilderung der beiden Seiten des Genfer Sees in Jean-Jacques Rousseaus Julie ou La Nouvelle Héloïse; ein Briefroman, der auch Humboldt in manchen seiner kontrastreichen Landschaftsdarstellungen stark mitbeeinflusst hatte. Ihr außerliterarischer Referenzpunkt, ihre Entsprechung in der außersprachlichen Realität ist freilich der Gegensatz zwischen den Kaffee- und Tabakanbaugebieten der Vuelta Abajo einerseits und den großflächigen Zuckerrohrplantagen andererseits. Es ist der Gegensatz - um mit Fernando Ortiz zu sprechen, zwischen Zucker und Tabak, der personifizierte Gegensatz des Contrapunteo cubano - den wir im Roman plastisch vor Augen geführt bekommen. Auf der dunklen Seite dieser zweigeteilten Landschaft war Villaverde selbst aufgewachsen. Dort hatte er bereits als kleiner Junge die Schrecken der Sklaverei aus nächster Nähe kennengelernt. In seinem berühmten Contrapunteo cubano del Tabaco y el Azúcar brachte der kubanische Anthropologe und Kulturtheoretiker Fernando Ortiz, mit dem wir uns in dieser Vorlesung ausführlich beschäftigt haben, diesen von Villaverde skizzierten physiognomischen Gegensatz auf die Formel: „El azúcar fue esclavitud, el tabaco fue libertad." - Der Zucker war die Sklaverei, der Tabak die Freiheit. ${ }^{24}$ In Cirilo Villaverdes berühmtem Roman ist dieser Kontrapunkt bereits deutlich skizziert.

Längst war die Zuckerproduktion zu jenem ökonomischen Prinzip geworden, das die kubanische Geschichte der kommenden beiden Jahrhunderte beherrschen sollte. Wenn Villaverde aus romanästhetischen Gründen auch nicht der Tabakanbau, sondern die als paradiesisch dargestellte Kaffeeplantage der Ilinchetas mit ihrer ,menschlicheren` Form der Sklaverei als Kontrapunkt zur Hölle der Zuckermühlen dient, so entwickelt der Romancier doch eine Differenzierung, welche die Schrecken der Sklaverei auf Gamboas Ingenio überaus plastisch darzustellen erlaubt. Die von der Zuckerproduktion ausgehende erhöhte Nachfrage nach Sklaven, die in der Person des Zuckerproduzenten und Sklavenhändlers Gamboa zum Ausdruck kommt, setzt jene sozioökonomische Entwicklung in

23 Villaverde, Cirilo: Cecilia Valdés, S. 487.

24 Ortiz, Fernando: Contrapunteo cubano del tabaco y el azúcar, S. 60. 
Gang, deren politische und moralische Folgen Villaverdes Roman nachzeichnet. Erst am Ende des Jahrzehnts, in welchem Villaverdes Cecilia Valdés o La Loma del Ángel erschien, wird die Sklaverei auf Kuba formal beendet werden, ohne dass damit gleichwohl eine politische und staatsbürgerliche Gleichstellung der ehemaligen Sklaven verbunden gewesen wäre. Eine solche erfolgte erst mit der Kubanischen Revolution von 1959.

Sind in bisherigen Deutungen die Qualitäten des Romans als historisches Gemälde der Kolonialzeit häufig und mit Recht herausgestellt worden, so gilt dies nicht für die Frage nach der ästhetischen Stimmigkeit, nach seiner Struktur als literarisches Artefakt. Von dieser ästhetisch-literarischen Frage glaubte man sich offensichtlich dispensiert. Dies ist insoweit erstaunlich, als dass mit dem Hinweis auf die dokumentarischen Vorzüge von Cecilia Valdés keinesfalls befriedigend zu erklären ist, warum dieser Erzähltext zu dem kubanischen Roman des 19. Jahrhunderts schlechthin avancieren konnte und noch heute ein breites Lesepublikum fasziniert. Zeugnisse von dessen unverminderter Ausstrahlungskraft sind neben seinen vielen Ausgaben und zahlreichen Zarzuela-, Radio- und Fernsehadaptationen ${ }^{25}$ die Neuschöpfungen der achtziger Jahre, etwa der mit großem Aufwand gestaltete Kinofilm Cecilia von Humberto Solás oder auch der Roman La Loma del Ángel (1987) des kubanischen Schriftstellers Reinaldo Arenas.

Die Würdigung der dokumentarischen Qualitäten ging allzu oft einher mit einer Abwertung der ästhetischen beziehungsweise spezifisch literarischen Realisierung. Immer wieder wurden dem Autor mangelnder Stilwille oder fehlende Vorstellungskraft vorgeworfen, sei sein Schreiben doch allzu sehr einem platten Realitätsverständnis verhaftet geblieben. Darüber wurden freilich allzu schnell gerade jene literarischen Techniken übersehen, die dem Roman zu seiner zweifellos gegebenen und auch anerkannten Sonderstellung verhalfen. Einige dieser Verfahren und Strategien sollen im Folgenden in der gegebenen Kürze analysiert werden.

Von besonderer Bedeutung scheint mir in diesem Zusammenhang die Aufmerksamkeit zu sein, welche Villaverde jenem Bereich des literarischen Werks widmete, den man mit Gérard Genette als Paratext bezeichnen kann. Dabei erfüllte insbesondere das von Villaverde signierte „Vorwort des Autors“ - über den erwähnten Informationscharakter hinaus - seine Funktion als Leseanweisung des Romans in überzeugender Weise. Denn die bis heute dominierende Lesart des Romans als getreues Gemälde, als „pintura fiel“ folgte genau jenen

25 Vgl. González, Reynaldo: Contradanzas y latigazos. La Habana: Editorial Letras Cubanas 1983, S. $40 \mathrm{f}$. 
Orientierungen, die Villaverde seinen künftigen Leserinnen und Lesern vorgab. Vor allem sein dort geäußertes ,pragmatisches“, faktentreues Verständnis des Realismus prägte die Rezeption des Romans:

Weit davon entfernt, Figuren und phantastische, unwahrscheinliche Szenerien zu erfinden oder zu fingieren, habe ich den Realismus so, wie ich ihn verstehe, bis zu dem Punkte getrieben, die Hauptpersonen des Romans bis aufs Haar genau, wie man gemeinhin sagt, zu präsentieren, gekleidet in die Roben, die sie zu ihren Lebzeiten trugen, und größtenteils unter ihren richtigen Vor- und Nachnamen, und sie bedienen sich derselben Sprache, welche sie in den historischen Szenen verwendeten, in welchen sie auftraten [...]. ${ }^{26}$

In seinem Paratext gibt uns Villaverde einige Leseanweisungen gemäß seines eigenen Verständnisses eines literarischen Realismus, mit dem wir uns noch ausführlicher beschäftigen werden. In seiner Cecilia Valdés o La Loma del Ángel führt uns der kubanische Schriftsteller vor Augen, was er selbst darunter versteht: schlicht die größte mimetische Treue einschließlich der Wiedergabe aller Details, wie sie in der Realität waren. Und in der Tat werden dem Lesepublikum eine Vielzahl historischer Figuren unter ihren authentischen Namen vorgeführt: Sie reichen vom spanischen Generalkapitän der Insel, Francisco Dionisio Vives, ${ }^{27}$ über Literaten und Soziologen wie José Antonio Saco bis zu Sklavenhändlern in Afrika wie Pedro Blanco ${ }^{28}$ oder Sklavenjägern in Kuba wie Francisco Estévez, ${ }^{29}$ dessen Diario del Rancheador Villaverde im Übrigen bearbeitet hatte und wenige Jahre später herauszugeben trachtete. ${ }^{30}$

Wir müssen an dieser Stelle einige erste Einschränkungen machen: So handelt es sich bei diesen historisch belegten Figuren freilich nicht um die Hauptpersonen seines Romans. Ihr Auftauchen im Verein mit den fiktiven, fingierten Gestalten im Rampenlicht warf gewiss auch auf letztere, ganz im Sinne des auktorialen Vorworts Villaverdes und des Romanverständnisses eines Walter Scott, nicht nur das Licht der Wahrscheinlichkeit, sondern der historischen Wahrheit. Auf Erfindung und Fiktion verzichtete Villaverde also keineswegs: Wir sollten dem kubanischen Schriftsteller folglich nicht auf den Leim gehen und ihm sein behauptetes, rein ,dokumentarisches‘ Verständnis von Realismus ungeprüft abnehmen!

26 Villaverde, Cirilo: Cecilia Valdés, S. 30.

27 Ebda., S. $334 \mathrm{ff}$.

28 Ebda., S. 212.

29 Ebda., S. 521.

30 Vgl. Friol, Roberto: Introducción. In: Villaverde, Cirilo: Diario del Rancheador. Revista de la Biblioteca Nacional José Martí (La Habana) 15 (1973), S. 49-61. 
Die hervorgehobene Authentizität des Erzählten verfolgte der kubanische Romancier mit einem weiteren paratextuellen Verfahren: der Einfügung von Fußnoten. Auch deren Funktion ist vorwiegend die Betonung historischer Faktizität des im fortlaufenden Text Berichteten und insbesondere der dort präsentierten Romanfiguren. Besonders schön ist diese Funktion erkennbar am auktorialen Kommentar bestimmter Details bei der Ermordung Tondás mittels der kurzen Fußnote „Histórico“. ${ }^{31}$ An derartigen Stellen tritt der Autor im wahrsten Sinne als Gewährsmann, als Auctor des Berichteten auf; ein literarisches Verfahren, das neben vielen anderen Charakteristika des Textes auf den Historischen Roman Scott'scher Prägung verweist.

Nehmen diese ,auktorialen' Fußnoten noch eine Zwischenstellung zwischen Paratext und ,eigentlichem' Text ein, so gibt es im fortlaufenden Romangeschehen geradezu obsessiv wiederkehrende Beteuerungen des Erzählers, es handle sich bei dem Erzählten um eine wahre Geschichte, eine „historia verídica““. ${ }^{32}$ Dass Villaverde hierbei auf die immer gleiche Formel zurückgreift, mag Anlass zur Kritik an stilistischen Schwächen des Romans bieten. Dieses Verfahren belegt aber vor allem, wie wichtig es dem Autor war, die der Leserschaft im Vorwort gegebene Orientierung im Text selbst aufzugreifen und damit die vorgeschlagene historisch-dokumentarische Lesart zu unterstützen. Dies erscheint verständlich, ist der Historische Roman doch immer auch eine spezifische Lesart, eine „manera de leer“, ${ }^{33}$ und musste es dem kubanischen Schriftsteller doch darum gehen, die von ihm nahegelegte dokumentarisch-mimetische Lektüreweise zu unterstützen und - wie die Rezeptionsgeschichte zeigt -erfolgreich abzusichern.

Bleiben wir noch - wie im Kapitel zu Periquillo Sarniento - beim Paratext von Cecilia Valdés. Zur paratextuellen ,Ausstattung“ des Romans gehört auch eine mit „El Autor“ unterzeichnete Widmung des Werkes „A las cubanas“, welche die Exilsituation Villaverdes, seine räumliche wie zeitliche Distanz zur Heimat akzentuiert. Diese Distanz erscheint im Roman ästhetisch vermittelt als Abstand zwischen erzählter Zeit und Erzählzeit, wobei hier mit ersterer die Ebene der „historia“ (1812-1831), mit letzterer die Zeitebene des Erzählers beziehungsweise der „narración“ (bis Ende der 70er Jahre) zu koppeln ist.

Das Spiel zwischen Erzählzeit und erzählter Zeit gibt Villaverde dabei die Möglichkeit, an bestimmte Ereignisse der erzählten Zeit spätere historische Ent-

31 Villaverde, Cirilo: Cecilia Valdés, S. 624.

32 Ebda., u. a. S. 103, 112, 174, 223, 414.

33 Vgl. Jitrik, Noé: De la historia a la escritura: predominios, disimetrías, acuerdos en la novela histórica latinoamericana. In: Balderston, Daniel (Hg.): The Historical Novel in Latin America. Gaithersburg: Hispamérica 1986, S. 13-29, hier S. 26. 
wicklungen anzuschließen; ein Verfahren, das auch fiktive Ereignisse häufig nicht mehr als Fiktionen, sondern als historische Fakten (oder doch zumindest als wahrscheinlich) erscheinen lässt. Denn sie werden gleichsam nachträglich beglaubigt und erhalten die Weihe der Historizität. Hierzu zählen beispielsweise Hinweise auf die Märtyrer des spanischen Kolonialregimes in Kuba anlässlich der sogenannten Conspiración de la Escalera ${ }^{34}$ von 1844, auf Hinrichtungen von 1852 oder die berüchtigte Ermordung von Studenten in Havanna $1871 .{ }^{35} \mathrm{Um}$,Anachronismen' - wie mehrfach kritisch eingeworfen wurde - handelt es sich hierbei nur vom Standpunkt der erzählten Zeit aus, nicht aber aus Perspektive der Erzählzeit: Der Roman ist folglich an manchen Stellen deutlich stimmiger als seine Kritiker. Auf die ideologische Funktion derartiger Stellen wird noch zurückzukommen sein!

Die erzähltechnische Prämisse für dieses Spiel ist die eines auktorialen, ,allwissenden' Erzählers, dessen Verlässlichkeit beim Lesepublikum zweifellos unumstritten ist. Dieser sorgt durch eine Vielzahl von Wendungen direkt an den Leser - der manchmal als mit Kuba wenig vertrauter Ausländer, häufiger aber als kubanischer Zeitgenosse erscheint - für eine geradezu mündliche Präsenz im Text: auch dies ein Signal für die Authentizität des Berichteten. Der Zweiteilung des aus dem Text abzuleitenden impliziten Lesers entsprechen wiederum bestimmte Textstrategien, die in Cecilia Valdés Anwendung finden. Auf den Leser der ersten, vielleicht aber auch auf jüngere Leser der zweiten Gruppe sind essayistische, analytische Passagen abgestellt, die den Plot oder „récit“, das eigentliche Handlungsgeschehen unterbrechen, historische Rückblicke geben oder zukünftige Entwicklungen Kubas skizzieren. Eher auf die zweite, mit den historischen Ereignissen wohlvertraute Lesergruppe bezogen, erscheinen andere Verfahren, etwa die oftmalige Einbeziehung der Leserschaft in ein kollektives „nosotros“, die an einen Erzähler und Leser gemeinsamen Erfahrungshorizont bezüglich der Geschichte Kubas appelliert. Das häufige Ansprechen der Leserschaft im Text, gekoppelt mit anaphorischen und kataphorischen Verweisen, die dem Leser Erzähltes wieder in Erinnerung rufen beziehungsweise - was seltener vorkommt - ihn auf Zukünftiges oder künftig zu Erzählendes vorbereiten sollen, ${ }^{36}$ zählt zu jenen Textelementen, die Villaverde den Techniken des Feuilletonromans entlehnte.

Es findet sich freilich auch eine andere Verwendung der ersten Person Plural, welche die Dominanz der extradiegetischen Erzählerposition einmal durchbricht,

34 Villaverde, Cirilo: Cecilia Valdés, S. $441 \mathrm{f}$.

35 Ebda., S. $151 \mathrm{f}$.

36 Ebda., S. 420. 
jene Außerhalbbefindlichkeit des Erzählers gegenüber dem räumlichen und zeitlichen Universum der Romanhandlung also, die eine Wendung an eine ebenso extradiegetische Leserschaft ermöglicht. Bei der Beschreibung der schönen Agueda Valdés nämlich behauptet der Erzähler, es handle sich hierbei um eine bloße „Kopie des Portraits jener Dame, eines Ölgemäldes des Malers Escobar, das wir in unserer Jugend in Ekstase betrachten konnten“. ${ }^{37}$ Dient der Verweis auf ein Werk des kubanischen Malers dazu, die tatsächliche Existenz dieser atemberaubenden Schönheit zu belegen, so ist auch das „nosotros“, sehr im Gegensatz zum berühmten Flaubert'schen „nous“, an derselben Funktion ausgerichtet. Denn die (zumindest kurzzeitige) Zugehörigkeit des Erzählers zur Vorgabe der erzählten Welt bürgt zusätzlich für deren historische Wahrheit und die mimetische Funktion des Schreibens. Die extradiegetische und allwissende Erzählerposition wird durch diese Passage in ihrer Gesamtheit jedoch nicht in Frage gestellt.

Die bisherige Analyse zeigte eine Vielzahl literarischer Techniken auf, mit Hilfe derer es Cirilo Villaverde verstand, die Erwartungshaltung seiner Leserschaft zu beeinflussen, ihre Lektüre zu steuern und auf das Dokumentarische, ja Zeugnishafte seines Romans zu lenken. Die Betonung der historischen Faktizität des Erzählten hat Rückwirkungen auf die Deutung des Erzählers. Es dürften nicht zuletzt die paratextuellen Strategien gewesen sein, die Verquickung von Romangenese, politischer Entwicklung und literarischer Transposition im „Vorwort des Autors“, welche die in vielen Rezeptionszeugnissen zu beobachtende Gleichsetzung des Erzählers von Cecilia Valdés o La Loma del Ángel mit dessen Autor provozierten. Gerade in Studien, denen es um den dokumentarischen Charakter des Romans zu tun ist, lässt sich dieses Phänomen, das von der Macht der recht konventionellen und auf den ersten Blick unauffälligen, vielleicht aber gerade deshalb so wirksamen literarischen Mittel zeugt, bis in die Gegenwart belegen. ${ }^{38}$ Villaverde verwandelte die ökonomische und soziale Realität seiner Zeit in von seinen Romanfiguren gelebte Wirklichkeit, ohne dass bei den meisten Lesern Zweifel daran aufkamen, dass es sich um eine dokumentarische Darstellung handelte.

Will man den spezifischen Ort zwischen Fiktion und Geschichtsschreibung bestimmen, den Villaverde mit seinem Werk einnahm, so sind zum Abschluss dieser kurzen Analyse der literarischen Techniken jene Passagen des Textes zu

37 Ebda., S. 630: „copia del retrato al óleo de esa dama, hecho por el pintor Escobar, que, cuando jóvenes, pudimos contemplar extasiados.“

38 Vgl. unter anderem Lamore, Jean: „Cecilia Valdés“: realidades económicas y comportamientos sociales en la Cuba esclavista de 1830. In: Casa de las Américas (La Habana) 19 (1978), S. 41-53, hier S. $47 \mathrm{f}$. 
untersuchen, die uns Hinweise auf literarische Gattungen und Traditionen, auf andere Autoren und Werke geben: Denn diese Bezüge definieren den Bewegungsspielraum zwischen Historiographie und Fiktionalität. Bei der Untersuchung dieser intertextuellen Beziehungen übernimmt der paratextuelle Bereich einmal mehr eine wichtige Funktion, ordnet der kubanische Autor seinen Roman doch bereits im Vorwort einer Literatur zu, deren Modelle Walter Scott und Alessandro Manzoni seien.

Die Tradition des Historischen Romans europäischer Prägung, in welche sich Cecilia Valdés einschreibt, wird durch ein weiteres paratextuelles Element betont, wobei gleichzeitig der literarische Raum des Romans signifikant erweitert wird die jedem Kapitel vorangestellten Motti. Fungieren diese, ganz in der Scott'schen Tradition, bezogen auf die Handlungsebene als Indikatoren für Problematik und Stimmung sowie als Kommentare der jeweils folgenden Kapitel, so situieren sie den Roman als Ganzes insbesondere durch die Verwendung der Signalwirkung bestimmter Autornamen innerhalb eines expliziten literarischen Raumes. Dieser wird durch die intertextuellen Relationen mit anderen Autoren und Werken im fortlaufenden Text weiter präzisiert. Die asymmetrische Beziehung lateinamerikanischen Schreibens mit Blick auf europäische Vorbilder wird dadurch einmal mehr eindrucksvoll bestätigt.

Eine frühere Untersuchung hat gezeigt, dass dieser literarische Raum eine Bipolarität zwischen europäischer und kubanischer Literatur aufweist, wobei die erstere insbesondere durch die Verwendung erwähnter Motti den Roman Villaverdes gleichsam legitimiert. ${ }^{39}$ Zeigt die kubanische Literatur ihrerseits deutlich die erwähnte Zweiteilung in einen exil- und einen inselkubanischen Bereich, deren Produkt Cecilia Valdés o La Loma del Ángel selbst ist, so erscheint die lateinamerikanische Literatur als nahezu inexistent. Dies ist ein überaus signifikanter Befund, weist doch die beobachtete Bipolarität des literarischen Raums ${ }^{40}$ als wichtige Vermittlungsschicht zwischen Gesellschaft und Literatur zurück auf die noch ungelöste Kolonialproblematik Kubas. Gleichzeitig wird deutlich, wie sehr sich der Literaturraum Karibik und speziell Kuba zum damaligen Zeitpunkt - aber auch später und bis heute noch - in grundlegender Weise von anderen Literatur-

39 Vgl. hierzu Ette, Ottmar: „Cecilia Valdés“ und „Lucía Jerez“: Veränderungen des literarischen Raumes in zwei kubanischen Exilromanen des 19. Jahrhunderts. In: Berger, Günter / Lüsebrink, Hans-Jürgen (Hg.): Literarische Kanonbildung in der Romania. Rheinfelden: Schäuble 1987, S. 199-224, hier S. 208 f. sowie 222.

40 Vgl. hierezu Ette, Ottmar: Eine Literatur ohne festen Wohnsitz. Fiktionen und Friktionen der kubanischen Literatur im 20. Jahrhundert. In: Romanistische Zeitschrift für Literaturgeschichte / Cahiers d'Histoire des Littératures Romanes (Heidelberg) XXVIII, 3-4 (2004), S. 457-481. 
räumen der lateinamerikanischen Welt unterschied. Hierfür ist gerade der literarische Raum, der innerhalb des Romans ausgespannt wird, ein wichtiger Indikator.

Die Analyse literarischer Techniken, Verfahren und Strategien Villaverdes sollte nicht die so häufig beklagten stilistischen Schwächen des Romans in Abrede stellen. Sie konnte aber - wie sich schon anhand der Analyse der Mise en abyme zeigte - belegen, dass Cecilia Valdés bei aller Konventionalität der ästhetischen Mittel in Hinblick unter anderem auf Handlungsaufbau, Zeitebenen, paratextuelle und intertextuelle Anlage eine literarische Struktur von hoher Kohärenz aufweist, welche ihre Wirkung auf die Leserschaft nicht verfehlte. Es gilt nun, die bisherigen Ergebnisse in Verbindung zu bringen mit jenen Aufgaben, die Villaverde seinem Roman innerhalb der Tradition des Historischen Romans zuwies. Mit anderen Worten: Es geht darum, den Ort des Romans zwischen literarischer Fiktion und historischem Diskurs in seiner ästhetischen wie gesellschaftlichen Funktionalität zu verstehen.

Wie bereits erwähnt, gehört Cecilia Valdés o La Loma del Ángel einer Gruppe abolitionistischer Romane an, welche die Schrecken der Sklaverei in Kuba moralisch anprangerten und die Öffentlichkeit dergestalt beeinflussen wollten, auf eine möglichst rasche Abschaffung des Sklaverei-Systems hinzuwirken. Ihr Verfasser zählte zum Kreis von Autoren um Domingo del Monte, dessen Position innerhalb des kubanischen literarischen Feldes, der Exilierung zum Trotz, noch weit bis in die zweite Hälfte des 19. Jahrhunderts eine beherrschende war. Der eindeutig abolitionistische Standort dieses Kreises ${ }^{41}$ wirkte sich inhaltlich direkt auf die Literatur aus: So ging der bereits erwähnte Roman Francisco von Suárez y Romero ursprünglich auf eine Bitte zurück, die der englische Abolitionist Madden gegenüber Domingo del Monte geäußert hatte. Ähnlichen Motiven entsprang die Autobiografía des ehemaligen Sklaven Juan Francisco Manzano, die von Madden 1840 ins Englische übersetzt wurde und bis heute zu den meistgelesenen abolitionistischen Erzähltexten gehört.

Auch in Cirilo Villaverdes Cecilia Valdés ist die Anprangerung und Verurteilung der Sklaverei allgegenwärtig. Im Gegensatz zu anderen Autoren knüpfte ihr Autor jedoch keinerlei abolitionistische Hoffnungen an das Erscheinen seines Werkes, wie er 1884 einem Brief an einen Freund anvertraute: „Im Übrigen halte ich die zivile Sklaverei für tot und ich sehe nicht, dass das Gemälde ihrer Schrecknisse, so dramatisch sie auch sein und so wahrhaftig sie auch gemalt sein mögen, die vollständige und absolute Abschaffung dieser hassenswerten Institution auch nur um einen Tag, eine Stunde oder eine Minute beschleuni-

41 Vgl. hierzu Vitier, Cintio: Prólogo. In (ders., Hg.): La crítica literaria y estética en el siglo XIX cubano. 3 Bde., La Habana: Biblioteca Nacional José Martí 1968-74, Bd. I, S. 16-35. 
gen könnte. Die Sklaverei des Weißen auf Kuba ist es, die mir weit mehr Sorgen macht. “42 Im Jahre 1884 freilich war auf Kuba die Sklaverei faktisch abgeschafft und bestand auf dem amerikanischen Kontinent lediglich in Brasilien noch bis ins Jahr 1888. Dass dies freilich nur die formale Abschaffung der Sklaverei betraf und andere Formen von Sklaverei sich bis heute fortsetzen, ist offenkundig. ${ }^{43}$

Die dominante Funktion des Romans, so sah es Villaverde schon kurz nach seiner Veröffentlichung, lag anders als bei den erwähnten literarischen Vorläufern vorrangig also nicht auf dem Gebiet eines Kampfes gegen die Sklaverei, die in Kuba im Übrigen 1886 auch de iure abgeschafft wurde. Sein Ziel war vordringlich die Abschaffung der „Sklaverei des Weißen“, eine Metapher, wie sie vom spanischen Sklavenhändler Gamboa unter umgekehrten Vorzeichen im Roman erläutert wird: „Der Aufseher spielt auf der Zuckerplantage dieselbe Rolle wie der Colonel in seinem Regiment oder der Generalkapitän vor den Vasallen seiner Majestät in dieser Kolonie. Wie sollte auch sonst die Ordnung, der Frieden und die Disziplin aufrechterhalten bleiben auf der Pflanzung, in der Kaserne oder im Generalkapitanat der Insel Kuba?“44

Wird die Sklaverei über ihre unmenschliche Realität hinaus in den Worten Gamboas und bei Villaverde also zur Metapher für das spanische Kolonialsystem überhaupt, so ist es die Überwindung des letztgenannten, welche auch die Zerstörung des Sklavenhaltertums mit sich bringen soll. Realgeschichtlich entspricht dieser Position die Ausrufung der Freiheit der Sklaven durch Carlos Manuel de Céspedes zu Beginn des Zehnjährigen Krieges von 1868 bis 1878, romanintern unter anderem die mehrfach angedeutete, wenn auch widersprüchliche Auflehnung des Kreolen Leonardo gegen seinen spanischen Vater, der die iberische Kolonialmacht an ihrer ökonomischen Flanke repräsentiert. Realgeschichtlich ist die Herausbildung einer kubanischen Identitätskonstruktion durch die ,nationale“ Erfahrung der „Guerra de los Diez Años“ gegeben, romanintern wird diese vermittelt durch eine Darstellung der Entstehung kreolischen Selbstbewusstseins

42 Zit. nach Friol, Roberto: Introducción, S-. 50: „Por lo demás, yo veo ya muerta la esclavitud civil y no considero que el cuadro de sus horrores, por dramático que sea, ni por verdadero que se pinte, podrá adelantar un día, una hora, un minuto, la abolición total, absoluta de esa odiosa institución. La esclavitud del blanco en Cuba, es la que más me preocupa ahora.“

43 Vgl. hierzu Zeuske, Michael: Handbuch Geschichte der Sklaverei. Eine Globalgeschichte von den Anfängen bis zur Gegenwart. 2., überarbeitete und erweiterte Auflage. 2 Bände. Berlin - Boston: Walter de Gruyter 2019.

44 Villaverde, Cirilo: Cecilia Valdés o La Loma del Ángel, S. 544: „El mayoral representa aquí [i. e. en el ingenio] el mismo papel que el coronel delante de su regimiento, o que el capitán general delante de los vasallos de S.M. en esta colonia. ¿Cómo, si no, se conservarían el orden, la paz ni la disciplina en el ingenio, en el cuartel o en la Capitanía General de la isla de Cuba?“ 
und vor allem der aktiven Fusion beziehungsweise Transkulturation der kubanischen Bevölkerung. Cecilia Valdés schildert diesen historischen Vorgang aufmerksam und mit vielen lebensnahen Details. An eben diesem Punkt gelangen wir zu jener zentralen literarischen Vermittlungsschicht, deren überzeugende Ausgestaltung sicherlich in hohem Maße mitverantwortlich ist für den Erfolg von Cirilo Villaverdes zweifellos berühmtestem Werk.

In einem 1832 veröffentlichten Essay über den Historischen Roman verlangte Domingo del Monte von einem Romancier in dieser bezüglich ihrer Komposition hochschwierigen Gattung, diesem „género dificilísimo de composición“, gleichzeitig „Poet, Philosoph und Antiquar“ zu sein. ${ }^{45}$ Dabei galten dem kubanischen Literaturpapst - und Villaverde pflichtete ihm hierin bei, wie wir sahen - Scott und Manzoni als die wahren Meister des Genres. Beschäftigten wir uns bisher überwiegend mit der dritten und der ersten, also der dokumentarischen und der spezifisch literarischen Komponente, so soll nun die ,philosophische‘ Ebene des Romans ins Blickfeld rücken: Denn auch auf diesem Gebiet hat er durchaus etwas zu bieten!

Die Funktion von Literatur im Sinne Cirilo Villaverdes entsprach der Auffassung des Kreises um Del Monte, der in Fortführung aufklärerischen Gedankenguts Literatur als Instrument gesellschaftlichen Fortschritts begriff. ${ }^{46}$ Über diese kubanische Literaturtradition hinaus verwies Villaverdes Roman auf die in ganz Lateinamerika nachweisbare Funktion des Historischen Romans als Suche nach dem Nationalen, der eigenen nationalstaatlichen Identität, ${ }^{47}$ welche in Kuba, der „siempre fiel isla de Cuba“, durch die verzögerte Entstehung des Nationalstaats in besonderer Weise problematisch war. Denn noch immer befanden sich Kuba, Puerto Rico und die Philippinen in direkter kolonialer Abhängigkeit von Spanien; eine Situation, welche sich erst gegen Ende des 19. Jahrhunderts auflösen sollte.

Bereits Andrés Bello, der im Übrigen als einziger Südamerikaner mit einem Motto in Cecilia Valdés vertreten ist, ${ }^{48}$ hatte auf die Notwendigkeit des Narrativen zur Darstellung der Geschichte des Subkontinents aufmerksam gemacht. ${ }^{49}$ Die

45 Del Monte, Domingo: Novela histórica [1832]. Wieder abgedruckt in Vitier, Cintio: Prólogo. In (ders., Hg.): La crítica literaria y estética en el siglo XIX cubano, 1968-74, Bd. I, S. 114-120, hier S. 117: „poeta, filósofo y anticuario.“

46 Vgl. hierzu Dessau, Adalbert: Die Anfänge des ästhetischen Denkens in Kuba 1830 bis 1850. In: Beiträge zur Romanischen Philologie (Weimar) 22 (1983), S. 7-19.

47 Vgl. Jitrik, Noé: De la historia a la escritura: predominios, disimetrías, acuerdos en la novela histórica latinoamericana, S. 17.

48 Villaverde, Cirilo: Cecilia Valdés o La Loma del Ángel, S. 453.

49 Vgl. Sommer, Doris: Not Just Any Narrative: How Romance Can Love Us to Death. In: Balderston, Daniel (Hg.): The Historical Novel in Latin America, S. 47-73, hier S. 49. 
Abdeckung von Funktionen der Geschichtsschreibung durch den Historischen Roman machte aber, wie Doris Sommer unterstrich, eine narrative Auffüllung der ,Lücken' des historischen Diskurses mit Hilfe von Liebesgeschichten unumgänglich. Diese Liebesgeschichten stellen in gewisser Weise jene Elemente des Plots bereit, mit Hilfe derer die Elemente der Story (im Sinne Hayden Whites) organisierbar werden. Sie bilden das Gerüst der zugrundeliegenden Allegorese - in deren Zentrum die Mulattin steht - und vermitteln die geschichtsphilosophischen beziehungsweise moralischen Elemente in den literarischen Text. An dieser Stelle greift die literarische Imagination und entfaltet die romaneske Fiktion ihr eigenes Recht; und eben hier kommt die ,erfundene‘ schöne Mulattin Cecilia Valdés hinzu.

Es ist dieser generative Aspekt, die Modellierung des Nationalen mit Hilfe der Liebesverbindung zwischen einem Weißen und einer Mulattin, welcher die Bedeutung von Cecilia Valdés als identitätsbegründendem und identitätsstiftendem Roman ermöglicht. An dieser Stelle haben wir es selbstverständlich auch im historischen Roman nicht mit historischen, sondern notwendig mit ,erfundenen“ Figuren zu tun. Die literarische Figur der Mulattin, die sich spätestens seit Ende des 18. Jahrhunderts in der Karibik nachweisen lässt ${ }^{50}$ und deren Siegeszug zumindest bei männlichen Autoren - bis heute anhält, bot sich hier als jenes Sinnbild an, anhand dessen es Villaverde gelang, die Fusion der kubanischen Gesellschaft literarisch vorzuführen und plausibel $\mathrm{zu}$ machen. Cecilias Großmutter Magdalena Morales war noch schwarz; die außerehelichen Verbindungen von Großmutter und Mutter jeweils mit Weißen aber ließen in ihrem ,Resultat' die junge Mulattin ,fast‘ zu einer Weißen werden, die der ehelichen Tochter Gamboas und Schwester Leonardos, Adela, dann zum Verwechseln ähnlich sieht. Eben dadurch macht uns der Verfasser darauf aufmerksam, dass die ethnische Dimension untrennbar mit der soziokulturellen verbunden ist.

Das beiden Liebenden unbewusste Inzesttabu vermag, allen Bemühungen von Vater und Großmutter zum Trotz, die Vereinigung Cecilias mit Leonardo nicht zu verhindern; zumal diese die immer wieder angedeuteten inzestuösen Neigungen des Sklavenhändlersohns zu Mutter und Schwester umlenkt und auf ein anderes Liebesobjekt fixiert. Doch Liebe ist nicht gleich eheliche Verbindung: Denn das Heiratsverhalten gilt nicht von ungefähr als der empfindlichste Gradmesser für die soziale Akzeptanz im Zusammenleben, in der Konvivenz zwischen unterschiedlichen ethnischen Gruppen. Leonardo verhält sich vorhersehbar ganz

50 Vgl. Phaf, Ineke: Motivforschung altmodisch? Mit der Mulattin zu einem karibischen Nationaltext. In: Kohut, Karl (Hg.): Rasse, Klasse und Kultur in der Karibik. Akten der Fachtagung „Rassebeziehungen und Rassebegegnungen in der Karibik“ am 15. und 16. Mai 1987 an der Katholischen Universität Eichstätt. Frankfurt am Main: Vervuert 1989, S. 85-98. 
dem verbreiteten Sprichwort gemäß: „La blanca para casar, la mulata para gozar y la negra para trabajar." In einer phallogozentrischen Gesellschaft also heiratet man die Weiße, verlustiert sich mit der Mulattin und hat die Schwarze, um sie für sich arbeiten zu lassen ...

Leonardo Gamboas Plan, in der kubanischen Sklavenhaltergesellschaft die weiße Isabel $\mathrm{zu}$ heiraten und die Mulattin Cecilia als „amante en titre“ $\mathrm{zu}$ behalten, scheitert jedoch, so ,klassisch' er auch ausgedacht war. Die Frucht der Liebesbeziehung mit Cecilia, ganz dem Walten einer Fatalität gehorchend einmal mehr ein hübsches Mädchen, „una hermosa niña“, ${ }^{51}$ beschleunigt die Zerstörung aller Zukunftspläne und endet in der Katastrophe jener Bluthochzeit, bei der Leonardo, von seinem unglücklichen Gegenspieler, dem Mulatten Pimienta ins Herz getroffen, zu Boden sinkt und verstirbt. Dass dieser ,Herztreffer‘ in einem romantischen Roman gerade Leonardo ereilt, ist selbstverständlich vorbestimmt, wird er doch an jenem zentralen Organ verwundet, dem er bei anderen so viel Schaden zugefügt hatte.

Die Mulattin erscheint im Roman als Vertreterin einer Kultur, in der Elemente spanischer und iberischer Herkunft mit afrikanischen und afrokaribischen Traditionen verschmelzen; eine Verbindung, die im Roman am anschaulichsten immer wieder in Musik und Tanz zum Ausdruck kommt: „el baile es un pueblo“, ${ }^{2}$ der Tanz ist das Volk. Tanz und Konkubinat sind für die schöne Mulattin andererseits Techniken des sozialen Aufstiegs in einer kolonialen Sklavenhaltergesellschaft, in der Cecilia ethnisch und als Frau deutlich marginalisiert ist. Ihre Welt ist nicht das Land, der Bereich der schwarzen Sklaven, in denen Villaverde - in einer Art impliziten Rassismus', wie heute kritisch anzumerken ist - im Grunde keine Träger einer eigenen Kultur erkennen kann: Sein Hauptaugenmerk richtet sich vielmehr auf das Ergebnis der Transkulturation, um es mit dem Zentralbegriff von Fernando Ortiz zu sagen.

Die Mulattin ist ganz im Gegensatz die Bewohnerin der kolonialen Stadt, die nicht zuletzt Ort der Verfertigung und Institutionalisierung der Literatur ist, wie dies vom Erzähler mehrfach dargestellt wird. Der Zusammenbruch dieser Literatur, ${ }^{53}$ den die ,anachronistischen' Kommentare des Erzählers bezeugen und dessen Opfer Villaverde selbst wurde, ist auch der Zusammenbruch des Versuchs einer Fusion, der Schaffung einer nationalen Identität, für welche die Geschichte der Mulattin Cecilia Valdés die Allegorie gewesen war. Alles geht in diesem kuba-

51 Villaverde, Cirilo: Cecilia Valdés, S. 731.

52 Ebda., S. 266.

53 Vgl. hierzu Fornet, Ambrosio: Literatura y mercado en la Cuba colonial (1830-60). In: Casa de las Américas (La Habana) 84 (1974), S. 40-52. 
nischen Roman des 19. Jahrhunderts zu Bruch. Alles? Die Tochter von Leonardo und Cecilia, jenes hübsche Mädchen, über dessen weiteren Lebensweg das Lesepublikum nichts mehr erfährt, lebt weiter. Der Mythos von Cecilia Valdés, der vielleicht einzige literarische Mythos der kubanischen Literatur bleibt lebendig und stark. Und mit ihm der Mythos eines mulattischen Kuba, für das im 20. Jahrhundert nicht nur der Name des Nationaldichters Nicolás Guillén stehen wird.

Erinnern wir nochmals daran: Das auf Mai 1879 in New York datierte und oben angeführte „Vorwort des Autors“ zu seinem 1882 im US-amerikanischen Exil erschienenen Roman führt literarische Darstellungsformen vor, die dem angestrebten Lesepublikum eine Orientierung an den vom Verfasser intendierten Sinnbildungsprozessen ermöglichen sollen! Die vom Autor in seinem Paratext entwickelten Vorstellungen lassen ein deutliches Bild darüber entstehen, wie sich der kubanische Schriftsteller die Aneignungsprozesse von Seiten seiner Leserschaft seinerseits imaginierte. Im Vorwort wird ein Rückgriff auf Erfindung (Inventio) und Fiktion unter Hinweis auf das (in der aristotelischen Tradition stehende) Wahrscheinlichkeitsgebot bestritten, dabei aber gleichzeitig eine Realismus-Konzeption präsentiert, die weit über die zu erzielende Wahrscheinlichkeit hinausführt. Wir hatten gesehen, dass der Roman den Bereich des Dokumentarischen integriert. Gegenüber der ,Unwahrscheinlichkeit‘ literarischer Illusionsbildung wird die Authentizität, ja Identität des präsentierten Textes mit dem Faktischen, mit Leben und Geschichte behauptet und damit für das eigene Werk ein der historischen Authentizität paralleler Status eingefordert. Doch gerade diese Nähe zum Leben und zum (vom Autor wie von der Leserschaft) Erlebten führt dazu, dass die Fiktion und mit ihr das fingierte Leben in ihr eigenes Recht treten.

Doch beschäftigen wir uns nochmals mit der Frage geschichtlicher Wahrheit und Glaubwürdigkeit und - vielleicht mehr noch - mit der Darstellung von Wirklichkeiten in Villaverdes Roman! Der kubanische Autor wollte von der Authentizität seiner Romanfiguren selbst jene überzeugen, welche die historischen Vorbilder persönlich kannten. Doch hatte er in seinem Vorwort keineswegs allein jene Leserinnen und Leser im Visier, welche die Hauptpersonen entweder persönlich oder über Erzählungen kennengelernt hatten; der Kreis einer intendierten Leserschaft ging weit über die kubanischen Lesekundigen hinaus. Cirilo Villaverde fühlte sich in seiner mimetischen Ausrichtung des Romans wie auch bezüglich der literarischen Techniken auf der Höhe seiner Zeit. Nicht ohne Stolz bezeichnete er sich expressis verbis als ,escritor realista tomando esta palabra en el sentido artístico que se le da modernamente“ ${ }^{54}$ mithin als einen realistischen Schriftsteller in einem künstlerisch-modernen Sinne.

54 Villaverde, Cirilo: Cecilia Valdés, S. 29. 
Im Vorwort blendet Villaverdes Hinweis auf eine über dreißig Jahre zurückliegende Lektüre seiner Romanvorbilder gleichzeitig die Entstehungsgeschichte des Romans ein, die in diesem Vorwort mit der Lebensgeschichte des Autors sowie der politischen Geschichte Kubas direkt und unauflöslich verknüpft wird. Diese Einheit von Roman, Leben und Geschichte fundiert die im Roman zur Anwendung kommende Mimesis autobiographisch und lebensgeschichtlich. Insofern die Entstehungsgeschichte des Romans bis in die dreißiger Jahre zurückreicht, die definitive Veröffentlichung von Cecilia Valdés aber in die achtziger Jahre fällt, umfasst der Text gleichsam die beiden sehr verschiedenartigen Hälften des kubanischen 19. Jahrhunderts. Wir haben es daher mit einem Roman des gesamten Jahrhunderts zu tun.

Dies betrifft auch das literarische Feld Kubas und dessen signifikante, für die karibische Area charakteristischen Veränderungen. Ausgehend vom Verhältnis zwischen historischer Entwicklung und lebensgeschichtlicher Entfaltung ergeben sich zwei für unsere Vorlesung wichtige Konsequenzen: Zum einen macht die Entstehungsgeschichte des Romans selbst schon auf die Existenz eines literarischen Feldes aufmerksam, welches in zwei Teile, nämlich Insel und Exil gespalten ist. Es handelt sich dabei um eine Spaltung, die durch eine Fülle innerliterarischer Verweise im Text in den Roman ästhetisch eingearbeitet ist. Und zum anderen wird die Leserschaft auf die Existenz zweier textkonstitutiver Zeitebenen vorbereitet, die sich ebenso - wie wir bereits sahen - auf Ebene des Romangeschehens wie auf historiographischer und lebensgeschichtlicher Ebene wiederfinden. Dergestalt deutet die Entstehungsgeschichte des Romans auf eine Lebensgeschichte und zugleich auf den langen Weg, den die kubanische Historie bis zur politischen Unabhängigkeit der Insel noch vor sich haben sollte.

Das Scheitern der Liebesbeziehung zwischen Leonardo und Cecilia verweist auf das Scheitern einer historischen Entwicklung, die allerdings in keiner Weise abgeschlossen ist, was die Existenz des hübschen Töchterchens - gleichsam einer neuen Cecilia - nachdrücklich betont. Logischerweise finden daher auch Ereignisse Eingang in den Roman, welche sich zwischen 1831 und 1879 ereigneten. Aus der Verbindung von Roman, Leben und Geschichte erscheint daher der Vorwurf, es handele sich um ,Anachronismen“ nicht nur unzutreffend, sondern irreführend: Cecilia Valdés ist in der Tat der Roman eines ganzen Jahrhunderts und seine Diegese ist - lebensgeschichtlich fundiert - eine doppelte, das gesamte Jahrhundert umspannende. Die Aneignung kubanischer Wirklichkeiten beschränkte sich nicht auf die pure Handlung des Romans.

Mit Vorliebe ging Cirilo Villaverde in seinem narrativen Werk von bestimmten „Faits divers“ aus, die ein Licht auf die kubanische Kolonialgesellschaft werfen konnten. Dieser Rückgriff auf lokale Ereignisse war ein probates Mittel auch der kubanischen Feuilleton-Literatur, die in den 30er Jahren wesentlichen Anteil an 
einer ersten Blütezeit der kubanischen Literatur besaß. An ihrem historischen Ausgang hatten wir den Roman $S a b$ von Gertrudis Gómez de Avellaneda kennengelernt, der in gewisser Weise eine literarische Konsequenz dieser ersten kubanischen Blütezeit ist, zugleich aber bereits in Spanien verfasst wurde. Wir können nun besser erkennen, dass die kubanische Literatur seit Beginn des 19. Jahrhunderts eine Literatur darstellt, welche keineswegs territorial an die Insel gebunden ist.

Auch ein Cirilo Villaverde profitierte von den Publikationsmöglichkeiten, die sich kubanischen Autoren in den Feuilletons der noch jungen Tagespresse der dreißiger Jahre boten, und produzierte bis zum sogenannten „fracaso social de la literatura“"55 auf Kuba in rascher Folge Erzählungen und Romane, die nach dem obligaten Umweg über die kolonialspanische Zensur oftmals rasch abgedruckt wurden. Von Ausgangspunkt und Wahl des Themas, aber auch von der Zentralstellung einer Liebesgeschichte her lassen sich also enge Verbindungen zwischen Cecilia Valdés und anderen narrativen Texten Villaverdes wie La joven de la flecha de oro oder El guajiro ziehen.

Die leichte Referentialisierbarkeit vieler Romanelemente bezieht sich zunächst auf Rahmenbedingungen der diegetischen Anlage und damit neben der erwähnten Zeit insbesondere auf Landschaften, Dörfer, Stadtviertel oder Häuser, welche im Verlauf des Romangeschehens zur Darstellung kommen. Viele Fahrten, Botengänge oder Besuche dienen vordringlich dem Ziel, für das Lesepublikum die nach ethnischen Gruppen und sozialen Klassen unterschiedenen Stadtviertel in wechselseitiger Kontrastierung zu beleuchten. Die Referentialisierbarkeit bezieht sich aber nicht zuletzt auf die Romanfiguren selbst, insofern sie Gestalten der kubanischen Geschichte darstellen.

Es gibt in der Tat eine Vielzahl historischer Figuren, welche die Romanhandlung beleben: $\mathrm{Zu}$ den bereits erwähnten zählen auch zahlreiche kubanische Literaten, die Villaverde mit besonderer Sorgfalt und viel Liebe porträtierte. Auf diese Weise wird in der Romandiegese bereits der literarische Raum aufgespannt, innerhalb dessen sich die intertextuellen Bezüge manifestieren. Die sich angesichts des Romanvorworts durchaus aufdrängende Vermutung, dass alle Figuren des Romans historisch beziehungsweise dem Autor persönlich bekannt gewesen seien, lag schon den Zeitgenossen nahe, wurde im Verlauf der Rezeptionsgeschichte immer wieder geäußert und führte sogar zum Verdacht, Villaverde habe die schöne Mulattin Cecilia Valdés selbst gut gekannt. Doch ist diese autobiographische Lesart nicht mehr als eine (vom Paratext wie verschiedentlich auch

55 Fornet, Ambrosio: Literatura y mercado en la Cuba colonial (1830-60). In: Casa de las Américas (La Habana) 84 (1974), S. 42. 
vom Romantext selbst gelegentlich geradezu provozierte) Variante des erwähnten und bislang dominanten Lektüremusters. Dass Cirilo Villaverde mit seiner Cecilia Valdés die Initialen teilt, legte ebenfalls eine autobiographische Lesart nahe.

Dies ist vor dem Hintergrund der literarischen Inszenierung historischer Figuren in den Werken Villaverdes durchaus verständlich, wenn auch irreführend. Denn der kubanische Romancier trennte die historisch verbrieften Gestalten nicht - wie dies etwa ein Honoré de Balzac tat - vom fiktionalen Personal seiner narrativen Texte. Er bevorzugte das traditionellere Modell des Historischen Romans à la Walter Scott: So ließ er historische und fiktionale Romangestalten immer wieder miteinander in eine Interaktion treten, welche die Glaubwürdigkeit und historische Legitimation des jeweiligen Textes erhöhte und auch auf die fiktionalen Figuren den Schein von Historizität warf. Das Scott'sche Modell war selbst in jenen Texten präsent, welche sich durch gewisse Abweichungen charakterisierten, etwa beim Rekurs auf weniger bekannte oder gar nur oral tradierte historische Figuren. So wandte der Autor sich beispielsweise gleich zu Beginn seines Romans El Penitente mit dem folgenden Verweis auf Walter Scott an seine Leserschaft:

Ich bin nicht Walter Scott und kenne daher weder Könige noch Königinnen, über die ich Erzählungen oder Geschichten verfassen könnte, doch besaß ich einen Geschichten erzählenden und gedächtnisreichen Großvater, der durchaus mit dem berühmten schottischen Romancier mithalten konnte, und so nehme ich mir vor, von verschiedenen Erzählungen so zu berichten, wie er mir berichtete, auch wenn sie nicht von gekrönten Häuptern erzählen, und Gott bezeuge, dass sie es verdienen, in Druckbuchstaben zur Unterhaltung und zum Troste des neugierigen Lesers niedergeschrieben zu werden. ${ }^{56}$

In dieser saloppen Passage wird nicht nur die Allgegenwart des Scott'schen Paradigmas deutlich, welches Villaverde bei seinen kubanischen Lesern voraussetzen konnte; es leuchtet auch die emanzipatorische Dimension einer Imitation europäischer Modelle in Lateinamerika auf, werden hier doch kubanische Zeitgenossen des Großvaters mit gekrönten europäischen Häuptern literarisch gleichgesetzt. Gleichzeitig wird eine mündlich vorgetragene volkskulturelle Erzählkunst mit einer schriftkulturellen Tradition auf eine Stufe gestellt sowie die mündliche Grundlage literarischen Erzählens in Lateinamerika herausgearbeitet. Darüber hinaus zeigt sich auch - und hierauf wird zurückzukommen sein -, wie Villaverdes Zugriff auf Realität häufig auf eine bereits vorangegangene (künstlerische) Bearbeitung derselben in Form mündlicher Erzählungen des Großvaters rekur-

56 Villaverde, Cirilo: El penitente. Novela de costumbres cubanas. La Habana: Editorial La Burgalesa 1925, S. 9. 
riert, ohne dass sich für ihn auf Grund dieser Tatsache eine Einbuße an Glaubwürdigkeit ergäbe.

In Cecilia Valdés hat Villaverde keineswegs nur die gesellschaftliche Führungsschicht, sondern nahezu alle Klassen und sozialen Fraktionen mit historischen Figuren durchsetzt, die häufig freilich im Hintergrund bleiben. Begrüßen sich historische und fiktive Gestalten im Roman, treten sie in eine Konversation oder gar in Unternehmungen ein, die historisch verbürgt sind, so ergibt sich der bei der Leserschaft bis heute nachprüfbare Effekt einer scheinbaren ,Entfiktionalisierung' fiktionalen Personals. Verschieben und Verwischen konventioneller Grenzziehungen zwischen Faktizität und Fiktionalität erleichtern als bewusste Schreibstrategien in wesentlichem Maße die Aneignung von Wirklichkeit durch das Lesepublikum: Wir erleben romanintern und fiktional einen Einbruch des Imaginierten in den Bereich geglaubter historischer Wirklichkeit. Mit anderen Worten: Die historisch referentialisierbaren Figuren beglaubigen das fingierte Personal als ein historisches - der Roman erlaubt die mimetische Aneignung fingierter Wirklichkeiten.

Auffällig ist, dass Villaverde seinen geradezu soziologischen Querschnitt durch die kolonialspanische kubanische Gesellschaft fast immer auch für einen Blick auf die Situation der jeweiligen Frauen nutzt. Auf diese Weise entsteht ein lebendiges Bild, ja ein Lebensbild der kubanischen Gesellschaft der ersten Jahrhunderthälfte vom Capitán General bis hinunter zu den Sklaven. Bleiben wir einen Augenblick bei den entlaufenen schwarzen Sklaven, den Cimarrones und ihren Jägern und Häschern! Der auf einem Zuckerrohr-Ingenio aufgewachsene Villaverde beschäftigte sich als Kenner der Materie mehrfach mit ihrem Schicksal. In diesen Zusammenhang gehört sein bereits erwähnter Diario del Rancheador, mit dem der kubanische Autor den entlaufenen Sklaven ein literarisches Denkmal setzte und uns Einblicke in die menschenverachtende Praxis der Jagd auf sie gewährte. Im Diario kam bei ihm ein Interesse an einem weithin vergessenen Segment der Bevölkerung Kubas zum Ausdruck, das zur Aufwertung dieser Gruppen durch die Forschungen von Fernando Ortiz wie zum testimonialen Roman Biografía de un cimarrón (1964) von Miguel Barnet im 20. Jahrhundert führte.

Beim Diario handelt es sich grob um eine von Villaverde edierte, grundlegend überarbeitete und umgeformte Fassung eines Tagebuchs, das der bereits erwähnte Sklavenjäger Francisco Estévez zwischen dem 5. Januar 1837 und dem 19. Mai 1842 führte. Ziel dieses Sklavenhändlers und Sklavenjägers, so heißt es in seiner eigenen Eintragung vom 5. Juli 1838, ist „el exterminio total de los cimarrones“, 57 folglich die totale Auslöschung aller entlaufenen Sklaven. Ich möchte an dieser

57 Villaverde, Cirilo: Diario del Rancheador, S. 57. 
Stelle nicht auf das recht aufschlussreiche Vorwort Villaverdes eingehen, das er auf New York am 28. Oktober 1885 datierte - also einige Jahre nach dem Erscheinen von Cecilia Valdés und fast ein halbes Jahrhundert nach den im Tagebuch berichteten Ereignissen. Wichtiger erscheinen mir die von Villaverde überarbeiteten Passagen von Estévez selbst, geben sie doch Einblick in die soziohistorische Situation Kubas, die alltägliche Grausamkeit der Sklaverei und der Sklavenjagd sowie - mentalitätsgeschichtlich nicht uninteressant - in die ganz normale Arbeit und die dazugehörige ideologische Absicherung eines als besonders effizient bekannten Sklavenjägers in der spanischen Kolonie.

Darüber hinaus kann man sich trotz aller Verzerrungen ein lebendiges Bild vom Leben entlaufener Sklaven im kubanischen „Monte“ machen. Es handelt sich um einen Bereich, der durch eine Vielzahl neuerer Arbeiten bereits recht gut aufgearbeitet ist und von dem uns ja bekanntlich die weltberühmt gewordene „Novela testimonio“ von Miguel Barnet, basierend auf Interviews mit dem bereits hundertjährigen ehemaligen schwarzen Sklaven und Cimarrón Esteban Montejo, anschauliche Einblicke vermittelte. Als Beispiele der gerade wegen ihrer Trockenheit in vielfacher Weise aufregenden Passagen seien hier zweie etwas ausführlicher zitiert; es geht zunächst um die überaus kostbaren Hunde des Sklavenjägers, die stets - in allen Berichten - eine große Rolle spielen:

Sie hatten zweifellos die erste Spur gefunden und stießen auf einen Palenque [d. i. eine Verschanzung entlaufener Sklaven], der von uns mehr als eine halbe Meile entfernt lag; wir verfolgten die genannte Spur, als wir den Klang einer Donnerbüchse hörten, die sie auf die Hunde abfeuerten; wir folgten ihrem Lauf dorthin, wo wir den Schuss gehört hatten, bis wir auf eine Höhle stießen, als wir eine Wand absuchten, und fanden die Hunde von Kugeln verletzt, aber niemanden sonst in dieser Höhle; wir untersuchten den ganzen Bereich etwa vier Viertel nach oben und fanden einen großen gerodeten Bereich vor, ließen die anderen Hunde los und folgten ihnen den ganzen Tag; am folgenden, dem 15., kehrten wir zurück, um die Rodungen zu erkunden, und fanden am 16. 7, die sie neu anlegten, und wir kalkulierten, dass diese umfriedeten Bereiche 50 bis 60 Neger aufnehmen könnten; wir fanden eine Menge Lanzen, die sie auf der Flucht zurückgelassen hatten, verschiedene Beutel mit feinem Pulver, spitze Messer mit einer Unzahl an Gewehrsteinen, wie sie in Tavernen verkauft werden, sieben oder 8 Schleppmassen in verschiedenen Größen, wodurch ich auf eine Anzahl von 667 Feuerwaffen komme, die sie besitzen; wir fanden auch etwa 14 oder 15 Bananenstauden, Schweinefleisch und Rindfleisch, etwa 40 alte Decken, viel Kleidung für Männer und Frauen, viele Töpfe und Kessel, was wir alles zusammentrugen und mit dem ganzen Umfriedungsbereich verbrannten; die Lanzen oder Speere warfen wir weg, wo sie diese nicht mehr finden würden, und brachten 10 zum Beleg mit, die wir im Hause von Don Manuel Sotolongo im Süden ließen, auf dem Gebiet von Santa Cruz. Seit dem 15. bis heute haben wir die Berge überprüft und die Kreuzungen nachts überwacht, wobei ich mir vorrechnete, dass wir ihnen begegnen müssten, da sie sich verstreut hatten: und in der Tat fingen wir am 17. einen, und am 21. hatten wir eine Begegnung mit 7, von denen wir zwei einfingen, 5 entflohen uns, von denen wiederum 2 auftauchten. [...] 
Wir durchstreiften die südliche Kordillere, und zwischen Rangel und dem Río de la Cruz fanden wir zwölf entlaufene Neger, welche in den Ebenen von Limones und San Bartolomé nach Lebensmitteln suchten; wir fielen über sie her und nahmen sie gefangen, von denen 3 Don Antonio de la Torre gehören, zweie Don Francisco Rodríguez und ein anderer Don Antonio Salvableta, einem Anwohner von Puerta de la Güira, ein weiterer aus dem neuen Dorf Limones und noch einer aus Santa Cruz; und zweie, die sich nicht ergeben wollten, stürzten sich von einer Wand herab und brachten sich um, zusammen mit dem besten Hund, der mir noch geblieben war; ich befragte die Lebenden, um herauszubekommen, wo sich denn die ganze Kohorte befände und wer ihr Anführer sei, und sie antworteten mir, dass dies Yará sei, der uralte Kapitän der Kohorte, und dass sie mir mehr nicht sagen könnten, weil sie erst neulich in die Berge geflüchtet und dass sie von vier der Alten geführt worden seien, von denen zwei die Toten seien und zwei weitere entflohen; am 17. kam ich zu meinem Haus, erstattete den Ehrenwerten Inspektoren Bericht und legte ihnen die Belege vor. ${ }^{58}$

Diese Passagen zeigen nicht nur die große Geschicklichkeit von Estévez bei der Verfolgung von Sklaven in den schwer zugänglichen, von Höhlen durchsetzten tropischen Gebirgswäldern Kubas. Mit ihrem trockenen, menschenverachtenden und alle Vorgänge genauestens beschreibenden Stil zeigen sie auch eine geradezu buchhalterische Mentalität und die nicht immer leicht zu lösenden Eigentumsprobleme bezüglich der Sklaven, wurde Estévez doch teilweise von den Sklavenhaltern auch direkt entlohnt und musste ebenso kolonialspanischen Stellen wie privaten Sklavenhaltern Rechenschaft über sein Tun ablegen. Er kannte sich bestens aus innerhalb der Gemeinschaft entlaufener Sklaven, die sich entweder in großen „Palenques“ oder (wie es im Originaltext heißt „Palanques“) zusammenschlossen, aber auch völlig unabhängig voneinander einsam wie Esteban Montejo oder in kleinsten Gruppen in den Bergen lebten.

In diesem Zusammenhang ist aufschlussreich, dass es gerade die unerfahrenen Cimarrones sind, die sich einfangen lassen, während die erfahreneren entweder entkommen können oder aber sich der erzwungenen Rückkehr in die Sklaverei - mit allen Prozeduren von Folterung, Verstümmelung und grausamer Bestrafung - durch den Freitod und damit einen letzten Akt eigener Entscheidung entziehen. Cirilo Villaverde machte auch in Cecilia Valdés o La Loma del Ángel auf unterschiedlichste Formen aufmerksam, wie sich die Sklaven auf Kuba Bestrafungen durch Selbstmord entzogen.

Die Spuren des Palenque weisen auf einen längerfristigen eigenen Lebensbereich hin, der freilich aufgrund der überblickbaren und eingrenzbaren Inselsituation Kubas niemals eine so große Ausdehnung besaß wie auf dem süd- und mittelamerikanischen Festland. Dort entwickelten sich derartige Palenques zu beeindruckenden parastaatlichen Gemeinschaften mit eigener Infrastruktur

58 Villaverde, Cirilo [Francisco Estévez]: Diario del Rancheador, S. 86 und 109. 
und offiziellen Ansprechpartnern, die von kolonialspanischer Seite bisweilen über lange Perioden politisch als Vertragspartner anerkannt wurden. In der Tat schlossen einige Palenques Verträge mit den Kolonialbehörden ab, ja schickten von ihnen unkontrolliert entlaufene Sklaven auch wieder an die weißen Kolonialherren zurück, um von diesen nicht weiter belästigt zu werden. Die politische Agency der schwarzen Sklaven war in der gesamten Area der karibischen Inselwelt wie auf den Festlandsäumen weit verbreitet und die entlaufenen Sklaven als Cimarrones, „Marrons“ oder „Maroons“ bekannt. Ihr Widerstand ging der Sklavenrevolution in Saint-Domingue teilweise um Jahrhunderte voraus.

Doch zeigen sich selbst auf Kuba Ansätze für recht dauerhafte soziale und kulturelle Gemeinschaften entflohener Sklaven, auf einer Insel also, wo bereits kurz nach der sogenannten ,Entdeckung‘ auf Grund der raschen Vernichtung der indigenen Bevölkerung schwarze Sklaven aus Afrika eingeführt und grausam zur Zwangsarbeit in der sich entwickelnden Plantagenwirtschaft gezwungen worden waren. Von Beginn an kam es immer wieder zu Sklavenaufständen, die zum Teil barbarische Racheaktionen zur Folge hatten, dabei aber die Sklavenhaltergesellschaft bisweilen in ihren Grundfesten bedrohten. Die dokumentierte Vielzahl an Aufständen kann nicht verwundern, war doch bereits im Jahre 1544 ein Viertel der Bevölkerung Kubas von schwarzer Hautfarbe; eine Tatsache, die oftmals übersehen wird. Die Schwarzen bildeten in ihren Gemeinschaften eine eigene kulturelle Welt. Doch erscheinen sie im Diario del Rancheador freilich nicht als Kulturträger, sondern allein in ihrer Eigenschaft als widerständiges und flüchtiges Eigentum, dessen man wieder habhaft $\mathrm{zu}$ werden versucht und $\mathrm{zu}$ diesem Zwecke eigens Sklavenjäger ausschickte. An einer Vielzahl von Stellen wird im Diario darauf verwiesen, dass bei getöteten oder in den Freitod gegangenen Sklaven deren abgeschnittene Ohren als Belege dienten und das Einkommen der angestellten Sklavenjäger sicherstellten.

Es gelang Cirilo Villaverde, seine statistischen Kenntnisse über die Bevölkerungszusammensetzung der Insel sowie seine Vertrautheit mit den Unterdrückungs- und Verfolgungsmechanismen des kolonialspanischen Regimes in seinen Roman Cecilia Valdés einzuarbeiten. Betrug der Bevölkerungsanteil der Weißen in „Gran Habana“ um die Jahrhundertwende noch $53 \%$, so sank er 1810 auf 43\% ab; der Anteil der „freien Farbigen“ stieg gleichzeitig von 22 auf 27\%, jener der Sklaven von 25 auf 30\%.59 Diese demographische Entwicklung verstärkte sich noch im weiteren Verlauf der ersten Hälfte des 19. Jahrhunderts. Um die Wende

59 Vgl. Zeuske, Michael / Munford, Clarence J.: Die „Große Furcht“ in der Karibik: Frankreich, Saint-Domingue und Kuba 1789-1795“, in: Ibero-Amerikanisches Archiv (Berlin) Neue Folge XVII, 1 (1991), S. 51-98. 
zum 19. Jahrhundert konnte der Anteil schwarzer Sklaven in einigen Regionen der Insel an $60 \%$ heranreichen. Diese Zahlenangaben lassen die weitreichenden ökonomischen Umstrukturierungen erahnen, welche die Umwandlung Kubas zum weltgrößten Zuckerproduzenten mit sich brachten; eine Entwicklung, die bewusst von der kreolischen Oligarchie in Interessenallianz mit der spanischen Kolonialbürokratie nach der Haitianischen Revolution eingeleitet worden war. Diese ökonomische, soziale und politische Entwicklung bildet den Hintergrund für Cecilia Valdés o La Loma del Ángel - und sie ist charakteristisch für die spezifische Area der Insel-Karibik wie des zirkumkaribischen Raumes.

Villaverde war freilich auch in anderen narrativen Texten um die Darstellung einer Totalität, eines gesellschaftlichen Querschnitts bemüht gewesen. So führte etwa die Erzählerfigur seines Romans El guajiro in kostumbristischer Manier den Leser anlässlich der Beschreibung eines Hahnenkampfs in die Sozialstruktur der weißen Landbevölkerung ein:

Dort war es, wo ein neugieriger Beobachter gemäß des Aussehens und des jeweiligen Habitus jedes Einzelnen die Klassen oder Stufen klassifizieren konnte, in die sich die Gesellschaft der Weißen einteilt, welche die Landgebiete der Insel bewohnen. Er würde den Verwalter des Ingenio am Ton der Überlegenheit und Befehlsgewalt erkennen, mit welchem er spricht und die einfachen Bauern betrachtet, aber auch an seinem schwarzen Stoffjackett oder auch an seinem rohen Leinenwestchen, der langen Krawatte und dem Panamahut; ebenso würde er den Vorarbeiter des Ingenio erkennen an [...]. ${ }^{60}$

Auf diese Weise werden allein in diesem sozialen Segment der Weißen des Weiteren der Zuckermeister („maestro de azúcar“), der „Boyero“, der Hausvorsteher („mayordomo de finca“) oder der einfache „Sitiero“ (in der verheirateten oder unverheirateten Variante) vorgestellt und entsprechend in Habitus, Kleidung und Sprache kostumbristisch in Szene gesetzt. Es handelt sich hierbei zweifellos um die Darstellung von Typen, die vorrangig anhand ihrer Kleidung und ihrer Sprache charakterisiert werden - ganz so, wie dies im eingangs zitierten „Prólogo del autor“ zu Cecilia Valdés angekündigt worden war. Diese dem Costumbrismo verpflichtete Dimension ist noch in Villaverdes Hauptwerk sehr präsent.

In der Tat findet sich im zuletzt genannten Text eine Charakterisierungsweise der Romanfiguren, welche neben der Beschreibung distinktiver Merkmale von Kleidung oder Lebensweise insbesondere die Sprache sowie spezifische Sprachformen oder -ticks berücksichtigt. Alle Schichten der kolonialspanischen Gesellschaft, vom Generalkapitän zur kleinen spanischen Händlersfrau, vom alten Sklavenaufseher oder jungen kreolischen Lebemann zum mulattischen Schneider

60 Villaverde, Cirilo: El guajiro. Cuadro de costumbres cubanas. La Habana 1891, S. 74. 
oder zum katalanischen Krämer, von der Frau des Plantagenbesitzers bis zum gerade aus Afrika geraubten Sklaven, dem „Bozal“, der des Spanischen noch nicht mächtig ist, werden durch bestimmte Formen mündlicher Sprache charakterisiert. Daher nimmt, was die russischen Formalisten „skaz“ nannten, ${ }^{61}$ also die Stilisierung verschiedenster Formen des alltäglichen mündlichen Erzählens, als literarische Technik eine überragende Stellung im Roman ein.

Bezüglich dieser Technik handelt es sich freilich nicht um „dieselbe Sprache“, welche die Protagonisten in den historischen Szenen gebrauchten, wie uns das Vorwort versichert hatte; wir haben es vielmehr mit literarischen Stilisierungen von Mündlichkeit zu tun, die keineswegs dem Gebot historischer Wahrheit, sondern den Regeln literarischer Wahrscheinlichkeit gehorchen. So ist die Sprache der Mulatten oder auch der Schwarzen wohl durch eine Vielzahl lexikalischer Besonderheiten, in geringerem Maße jedoch ebenso durch die Berücksichtigung der phonetischen Realisierung spezifischer syntaktischer Strukturen repräsentiert. Wohl wäre der auf einer Sklavenplantage aufgewachsene Villaverde zu einer korrekten Wiedergabe dieser Sprachformen fähig gewesen; ein großer Teil seiner Leserinnen und Leser - insbesondere auch nicht-kubanische Lesersegmente, welche der Romancier durchaus im Blickfeld hatte - wären aber kaum in der Lage gewesen, eine in solcher Form wiedergegebene Sprache zu verstehen. Villaverde brachte das in Anschlag, was als literarische Sprache überzeugend und wahrscheinlich war.

Ließe sich dies auch anhand einer Vielzahl von Beispielen einer Darstellung der spezifischen Sprache schwarzer Sklaven aufzeigen, so mag ein Dialog durch eine verbarrikadierte Tür zwischen einem kleinen katalanischen Händler, der des Nachts von einem potentiellen Käufer aus dem Bett geholt wird - in Wirklichkeit ein flüchtiger Mulatte namens Malanga -, vielleicht am anschaulichsten die Art der Stilisierung mündlicher Rede wiedergeben:

¿Y per questa embajat m'ha fet salir del cama? Andat, andat tu camin, Malangue. Jo no abrirat le porta. ¡Qué cinich descaro!

-Abra, ño Juan, pol er amol de su maire. Ahí está un probe moreno jerío.

- ¿Ferido dises? Pera el diable que te abra. ¡Mare de Deu ${ }^{12}$

61 Vgl. Ejchenbaum, Boris: Die Illusion des „skaz“. In: Striedter, Jurij (Hg.): Russischer Formalismus. Texte zur allgemeinen Literaturtheorie und zur Theorie der Prosa. München: Fink 1981, S. $161-167$.

62 Villaverde, Cirilo: Cecilia Valdés, S. 619: „Un dadrum heschmi usm Bett gschmisse? Kumm jetz gohsch, Malangue. Imoch net uff, Du spinnschwol! / Uffmache, Herr Johann, um Gottswille. Binne armer verwundeter Scharze. / Was, auno verwundet? Zumdeifel midir, imoch nit uff, bide Muoter Gottis!“ 
Handelt es sich hierbei um sprachliche Typisierungen, welche durch eingestreute Heterostereotype in ihrer Glaubwürdigkeit verstärkt werden - erst das Zauberwort „diné“ räumt alle Bedenken des katalanischen und folglich allein am Geld interessierten Krämers aus dem Weg -, so werden im Gegensatz dazu die Hauptpersonen von Cecilia Valdés auch auf Ebene ihrer Sprachverwendung (stilistisch) individualisiert. Individueller sprachlicher Habitus, Idiolekt und Soziolekt finden dabei literarische Berücksichtigung. Die Sprache des Romans wird damit - ganz im Sinne Michail Bachtins ${ }^{63}$ - zu einem System von Sprachen und transformiert sich zu einer Vielsprachigkeit, welche die unterschiedliche Perspektivik ihrer Sprecher manifestiert.

In diesem Kosmos der Redevielfalt treten diese Sprachen in einen Dialog ein, der von Herrschaftsstrukturen gekennzeichnet ist. Sie beleuchten sich dabei wechselseitig und vermitteln auf diese Weise soziale, politische oder ideologische Strukturen als sprachliche Formgebungen in den Roman. Dadurch kommt in der ostentativen Sprachenvielfalt des Romans auch eine an unterschiedliche Perspektiven gebundene Weltsicht zum Ausdruck, in welcher sich die Polylogik der Aneignungen von Wirklichkeiten niederschlägt.

Im Gegensatz zu anderen narrativen Texten Villaverdes wird in Cecilia Valdés o La Loma del Ángel nur noch bei den Nebenfiguren eines bestimmten sozialen Typus eine bestimmte Sprache zugeordnet, was nicht zuletzt im soeben zitierten Dialog zum Ausdruck kam. Vielmehr wird in seinem Meisterwerk der Polylog verschiedener Sprachen, wenn auch in unterschiedlich starker Weise und keineswegs durchgehend, in einzelne Personen selbst verlagert. Dadurch gewinnen die Hauptfiguren zusätzlich an Tiefe: Konflikte zwischen verschiedenen nicht miteinander völlig kompatiblen Diskursen brechen als individuelle und in den jeweiligen sozialen Kontext eingebettete Widersprüche auf.

Sprachliche Redevielfalt macht somit ein gewichtiges Stück der polylogischen Anlage des kubanischen Romans aus. Als Beispiel hierfür mag Doña Rosa dienen, die Frau des spanischen Zuckerrohrplantagenbesitzers unde Sklavenhändlers Gamboa, die im Dialog mit ihrem Sohn Leonardo das Tun ihres Mannes verteidigt:

Komm' mir nicht mit Deinen Prinzipien, mit Deinen Zwecken und Deinen römischen Gesetzen. Sie mögen besagen, was Du magst, die Wahrheit ist, dass es einen großen Unterschied gibt zwischen dem Verhalten Deines Vaters und dem von Don Pedro Blanco. Denn der letztere befindet sich dort, im Lande dieser Wilden; er beschafft sie für den Handel, er ist es, der sie durch Tausch oder Täuschung einfängt, er ist es, der sie gefangen setzt und für den Verkauf in diesem Land bereitstellt; wenn es also darin irgendein Verbrechen,

63 Vgl. Bachtin, Michail M.: Das Wort im Roman. In (ders.): Die Ästhetik des Wortes. Herausgegeben von Rainer Grübel. Frankfurt am Main: Suhrkamp 1979, S. 154-300. 
irgendeine Schuld geben sollte, dann fällt sie auf ihn, aber ganz gewiss nicht auf Deinen Vater. Bei genauerer Betrachtung ist Gamboa weit davon entfernt, irgendetwas Schlechtes oder Hässliches zu tun, er tut vielmehr Gutes, etwas, das es zu rühmen gilt, denn wenn er diese wilden Menschen aufnimmt und wohlgemerkt als Mitunterzeichner verkauft, dann geschieht dies, um sie zu taufen und ihnen eine Religion zu geben, welche sie in ihrem Lande nicht besitzen. ${ }^{64}$

In diesem Zwiegespräch wird in der Konfrontation zwischen Mutter und Sohn unter dem Druck der (im Übrigen recht unbedarften, da von Leonardo gerade erst schlecht erlernten) juristischen Argumentation des Sohnes eine Rechtfertigung erzwungen. Diese lässt recht ungeschickt von Seiten Doña Rosas - der alte Gamboa wäre gewitzter gewesen -, aber geschickt natürlich für die Ziele und Zwecke eines abolitionistischen Romans, mehrere Legitimationsdiskurse miteinander kollidieren. Nach dem Negieren juristischer oder allgemein ethischmoralischer Argumente führt Doña Rosa einen merkantilistisch-kapitalistischen Diskurs ins Feld, der in unserem Auszug durch einen christlichen beziehungsweise heilsgeschichtlichen Diskurs überdacht und damit überhöht werden soll. Es handelt sich um vorgefertigte Diskurse, die von den Familien und Familienoberhäuptern, welche durch den höchst einträglichen Handel mit schwarzen Sklaven hohe Geldsummen verdienten, im 19. Jahrhundert mit großer Regelmäßigkeit gebraucht wurden. Cirilo Villaverde passt diesen scheinheiligen, aber durchaus effizienten Diskurs lediglich den Absichten und Handlungszusammenhängen seines Romans ein wenig an.

Die Bekehrung der ,Wilden' zum ,wahren Glauben', eine probate Legitimations- und Verschleierungsstrategie in Sklavenhaltergesellschaften, schießt jedoch über ihre diskursstützende Funktion hinaus und affiziert den erstgenannten kapitalistischen Diskurs. Auf diese Weise wird der in Afrika Sklaven pressende (und historisch verbürgte) Pedro Blanco argumentativ preisgegeben, gehorche er doch nicht den Regeln des Christentums, sondern jenen des Geldes. Der so profitable Dreieckshandel wird nicht als gesamtes ökonomisches Gebilde akzeptiert, sondern in positive und negative Seiten zerlegt. Damit ist der Legitimation des Sklavenhandels allerdings in ihrer Gesamtheit implizit der Boden entzogen: Die christliche Legitimation, die doch dem gesamten Sklavenhandel galt, wird nur noch für die letzte Etappe, die (berüchtigte), Eingewöhnungsphase' der Sklaven auf Kuba, geltend gemacht. Villaverde zeigt den Legitimationsdiskurs, um ihn sogleich zu dekonstruieren und in seine Einzelteile zu zerlegen.

64 Villaverde, Cirilo: Cecilia Valdés, S. $212 \mathrm{f}$. 
In dieser Passage wird auf vereindeutigende Erzählerkommentare verzichtet, wenngleich Villaverde hinsichtlich des zutiefst christlichen Rechtfertigungsdiskurses an anderer Stelle auch auf dieses Mittel zurückgreift, etwa wenn er Doña Rosa als eine christliche, barmherzige und den Armen Almosen gebende Frau charakterisiert, die aber ungerührt und unbarmherzig der Misshandlung schwarzer Sklaven gegenüberstehe. ${ }^{65}$ An wieder anderer Stelle verweist er noch geschickter auf offizielle Verlautbarungen der „comisión militar permanente“, ${ }^{66}$ welche er seinen Romanfiguren in den Mund legt, finden sich derartige Äußerungen doch wieder abgedruckt in den einschlägigen Tageszeitungen wie dem Diario de La Habana, den seine Protagonisten lesen.

Vermittels einer dialogischen In-Bezug-Setzung verschiedener literarisch stilisierter Sprachen und Diskurse wird so eine gesellschaftliche Totalität als sprachliche in Szene gesetzt. Selbst in den so häufig zitierten spanischen oder kubanischen Sprichwörtern, mehr aber noch in den Äußerungen der Romanfiguren selbst, ist jene „Mehrstimmigkeit des Wortes im Roman“ präsent, welche Bachtin für die Entwicklungsgeschichte des europäischen Romans so überzeugend nachweisen konnte. Im Sinne des russischen Literaturtheoretikers treffen dabei gerade im ,fremden“ Wort die gesellschaftlich und kulturell verankerte Sprache der Figur und jene des Autors - wir dürfen hier abweichend hinzufügen: des impliziten Autors $^{67}$ - zusammen. Im Gegensatz zu den Nebenfiguren verkörpern die Hauptfiguren in Cecilia Valdés o La Loma del Ángel nicht mehr in kostumbristischer Manier bestimmte soziale Typen, sondern bringen eine Vielfalt von Perspektiven, Sprachen und Diskursen zum Ausdruck, was durch eine kohärente, teilweise konventionelle, immer aber wirksame literarische Struktur ermöglicht wird. Villaverdes Roman ist alles andere als literarästhetisch belanglos!

Im Kern dieser Struktur steht die Figur des Erzählers. Erst deren Anlage setzt die bislang dargestellten literarischen Techniken in eine ästhetisch wirksame Beziehung zu jenen Funktionen, die Villaverde seinem Romanschaffen zuweist. Die vom kubanischen Schriftsteller modellierte Erzählerfigur ist - gemäß der von Gérard Genette entwickelten Kategorien - extradiegetisch, heterodiegetisch

65 Vgl. hierzu die Erzählerkommentare in Villaverde, Cirilo: Cecilia Valdés, S. 525: „Doña Rosa, mujer cristiana y amable con sus iguales, que se confesaba a menudo, que daba limosna a los pobres, que adoraba en sus hijos, que en abstracto al menos estaba dispuesta a perdonar las faltas agenas para que Dios, que está en el cielo, la perdonara las suyas; doña Rosa, sentimos decirlo, al ver las contorsiones de aquellos a quienes la punta del látigo de cuero trenzado del mayoral abría surcos en sus espaldas o brazos, se sonreía [...]“

66 Ebda., S. 531.

67 Vgl. zur Begrifflichkeit Link, Hannelore: Rezeptionsforschung. Eine Einführung in Methoden und Probleme. Stuttgart - Berlin: Kohlhammer ${ }^{2} 1980$, S. 25 und passim. 
und über alles im Bilde („focalisation zéro“), mithin allwissend. Sie steht außerhalb der räumlichen und zeitlichen Dimensionen des Romangeschehens, nimmt damit also eine von diesem prinzipiell getrennte Position ein. Auf diese Weise kann die Erzählerfigur eine effektive Vermittlerrolle zwischen Romandiegese und (realer) Leserschaft übernehmen. Die Funktion des Erzählers als Schaltstation wird romantechnisch realisiert, indem der implizite Leser in betont mündlicher Sprache immer wieder angesprochen wird, wodurch - wie bereits erwähnt - die Doppelung des intendierten Leserkreises in eine kubanische und eine nicht-kubanische Leserschaft als konstitutives Element in den Text eingeblendet wird.

Die so ausgestattete Figur des Erzählers ist die erzähltechnische Voraussetzung für die Anordnung und Strukturierung der narrativen, deskriptiven und diskursiven Partien des Romans. Dabei ist die für den Roman so zentrale Auffächerung zwischen der Ebene des „récit“ und der Ebene der „narration“ (ungenauer bleibt die erwähnte Unterscheidung zwischen erzählter Zeit und Erzählzeit) im „Prólogo del autor“ paratextuell in der Schaffung einer Autorfigur angelegt worden. Dieser implizite Autor, der als „Autor schlechthin“(d.h. als realer Autor) ausgegeben und durch die Signatur mit Villaverde gleichgesetzt wird, überträgt im Verlauf des Romangeschehens durch eine Vielzahl von Kommentaren und Einschüben seine erzähltechnischen Funktionen an die Erzählerfigur, mit der er nahezu eins wird. Auf diese Weise wird die Figur des Erzählers an den realen Autor rückgebunden, so dass dem Text - wie bereits betont - eine autobiographische Dimension zuwächst, welche sich gerade auch auf die diskursiven Teile, den historischen Rückblick oder Erläuterungen an die Adresse eines nicht-kubanischen Lesers ausdehnt. Roman, Leben und Historie werden, um es nun aus veränderter Perspektive nochmals zu betonen, effizient eng- oder zusammengeführt.

Die autobiographische Sinnbildungsebene wird durch eine Reihe eingewobener Elemente verstärkt. Hierzu zählt auf inhaltlicher Ebene etwa die Tatsache, dass Cecilia Valdés - schenkt man dem Erzähler Glauben - nicht allein die Initialen mit Cirilo Villaverde teilt, sondern darüber hinaus im selben Jahr wie der kubanische Schriftsteller geboren wurde. Um auf einen berühmten Satz von Gustave Flaubert zurückzugreifen: „Cecilia Valdés, c’est moi“, hätte Villaverde sagen können.

Die autobiographische Unterströmung des Romans verstärkt freilich nur die Strategien und Effekte, die von Beginn des Vorworts an nicht nur Abbildanspruch, sondern Anspruch auf historische Authentizität geltend machten. Die Verwischung der Grenzziehungen zwischen realem Autor, implizitem Autor und Erzähler dient damit der ästhetisch wirkungsvollen Illusionsbildung, die Leserschaft habe es mit einem nicht-fiktionalen (wenn auch literarischen) Text zu tun, welcher tief in die Lebensgeschichte seines realen Autors eingewoben sei. Die Wirksamkeit dieser Effekte zeigt sich bis heute in der so häufigen Verwechslung 
zwischen Autor und Erzählerfigur, in der Gleichsetzung des Erzählers mit Cirilo Villaverde, wie wir dies beispielsweise bei Julio Sánchez ${ }^{68}$ oder Jean Lamore, ${ }^{69}$ aber auch bei vielen anderen Kritikern bis heute beobachten können.

Das Gemälde als Abbild des Faktischen ist in Cecilia Valdés ohne Zweifel die Lieblingsmetapher für den Bezug zwischen Werk und Wirklichkeit. So überrascht es auch nicht, dass etwa zur Bestärkung der Authentizität des Erzählten auf ein Bild des Malers Escobar zurückgegriffen wird, welches in der oben angeführten Passage als Garantie der Transposition von faktischer Realität in den literarischen Text erscheint. Auch in diesem Beispiel greift der literarische Text Villaverdes nicht direkt auf die Wirklichkeit zu, sondern bedient sich häufig zwischengeschalteter Gattungen oder Texte in einem sehr weiten Sinne. Der Erzähler greift explizit auf offizielle Verlautbarungen, mündliche Erzählungen oder journalistische Texte und Dokumente zurück. Es leitet ihn das Bestreben, in den Bereich nicht nur der künstlerischen Wahrscheinlichkeit und Glaubwürdigkeit, sondern in jenen historischer Faktentreue und Wahrheit vorzustoßen, der leicht von der Leserschaft überprüft werden könnte. In diesem Zusammenhang ist aufschlussreich, dass im Roman diesen Intertexten, handelt es sich bei ihnen auch um mehr oder minder stark ideologisch oder künstlerisch strukturierte Darstellungen von Wirklichkeit, ein erhöhtes Maß an Authentizität zugesprochen wird, was selbst noch für die ,Dokumentation“ in Form eines künstlerischen Gemäldes gilt oder reklamiert wird.

Doch gestalten sich die intertextuellen Verweisrelationen wesentlich komplexer, als dies anhand einer kurzen Untersuchung der Funktion zwischengeschalteter Texte erscheinen könnte. Schreibt sich der Roman - wie wir sahen - in eine doppelte, inselkubanisch und exilkubanisch verfasste Literaturgeschichte schon durch seine eigene Entstehungsgeschichte ein, so kommt dem Verweis auf die europäische Literatur vorrangig eine legitimierende Funktion hinsichtlich des eigenen Schreibens zu. Die Wirksamkeit dieser Funktion zeigt sich auch in der Tatsache, dass die Vielzahl an Motti, Zitaten und Verweisen - ganz wie in Domingo Faustino Sarmientos Facundo oder José Mármols Amalia - auf die europäische und speziell in Villaverdes Schreiben auf die spanische Literatur von den Zeitgenossen so interpretiert werden konnte. Ein Beleg dafür darf in einer Besprechung von Cecilia Valdés in der madrilenischen Revista de España erblickt werden. In dieser Rezension schloss der anonyme Verfasser seinen nur wenige Jahre nach Veröffentlichung des Romans erschienenen Beitrag mit den Worten:

68 Vgl. Sánchez, Julio C.: La obra novelística de Cirilo Villaverde. Madrid: De Orbe Novo 1973. 69 Vgl. Lamore, Jean: ,Cecilia Valdés': realidades económicas y comportamientos sociales en la Cuba esclavista de 1830, in: Casa de las Américas (La Habana) XIX, 110 (1978), S. 41-53. 
„Über das bereits Gesagte hinaus beglückwünschen wir Herrn Villaverde aufrichtig für seine profunde Kenntnis unserer nationalen Literatur und Sprache, insofern er sich der vielen Stücke unserer Klassiker bedient, mit denen er zahlreiche Kapitel seines Werkes eröffnet und Vokabeln und Wendungen verwendet, welche reinsten kastilischen Ursprungs sind. ${ }^{\text {" }} 0$ Man wusste es in Spanien zu danken, wenn in einem lateinamerikanischen Roman die spanische Literatur- und Sprachtradition besonders hervorgehoben wurde, war das Land doch infolge des geokulturellen Dominantenwechsels als intertextueller und literarischer Bezugspunkt weitgehend aus den spanischsprachigen Literaturen Amerikas verschwunden.

Es wäre sicherlich falsch und irreführend, in der spezifisch literarischen Legitimationsstruktur einen Widerspruch zur textintern suggerierten dokumentarischen Lesart beziehungsweise der Behauptung historischer Authentizität erblicken zu wollen. Beide Legitimationsstrategien sind vielmehr komplementär zu verstehen, denn sie sichern Cecilia Valdés nach beiden Seiten hin ab. Der Roman des kubanischen Schriftstellers verleugnet keineswegs seinen Status als literarisches Artefakt: Behauptet wird lediglich die Abkehr von Imagination und fiktionaler Gestaltung.

So kann dann auch die „histoire“ auf Ebene des „récit“ in Cecilia Valdés als Liebesgeschichte inszeniert werden. Anhand der inzestuösen Liebe zwischen dem reichen Kreolen Leonardo Gamboa und der schönen, von der weißen kolonialspanischen Gesellschaft marginalisierten, aber für alle Weißen begehrenswerten Mulattin Cecilia Valdés werden die Elemente der „histoire“ in einen Handlungsablauf überführt, dem die deskriptiven und diskursiven Romanteile zugeordnet werden. Dabei scheint mir die Kritik ${ }^{71}$ am Verfahren Villaverdes, die großen politischen Ereignisse des dargestellten Zeitraums selten in die Handlung einbezogen und häufiger durch Erzählerkommentare eingeblendet zu haben, sie mit anderen Worten also weniger auf der Ebene des „récit“ als auf jener des „discours" angesiedelt zu haben, ins Leere zu gehen. Denn eine derartige Kritik beruht auf der von Lukács vorgetragenen normativen Sichtweise des (europäischen) Historischen Romans und berücksichtigt nicht, dass gerade durch die Anwendung dieses Verfahrens narrative Möglichkeiten frei werden, die eine wesentlich stär-

70 Zitiert nach Sánchez, Julio C.: La obra novelística de Cirilo Villaverde, S. 173; die Besprechung erschien in der „Sección bibliográfica“ der Revista de España (Madrid) 101 (1884-1886), S. 474477 und lautete im Original: „A más de lo dicho, felicitamos sinceramente al señor Villaverde, porque revela un verdadero conocimiento de la literatura y lengua nacional en los múltiples trozos de nuestros clásicos, con los que encabeza los capítulos de su obra, y en el empleo de vocablos y locuciones del más puro origen castellano.“

71 Vgl. etwa Dorr, Nicolás: Cecilia Valdés: ¿novela costumbrista o novela histórica? In: Unión (La Habana) 1 (1970), S. 157-162. 
kere symbolische Kraft entwickeln können. Die Verwandlung von Cecilia Valdés in einen literarischen Mythos Kubas ist ein beredtes Beispiel für den Erfolg einer derartigen literarästhetischen Strategie.

Denn so können die gleichsam unterhalb der gewiss wichtigen politischen Ereignisse der dreißiger Jahre wirkenden demographischen, sozialen oder kulturellen Entwicklungen in der literarischen Ausgestaltung bestimmter Figuren des Romans zum Ausdruck gebracht werden. Nicht als historisch akkreditierte Protagonistin inmitten politischer Ereignisse, sondern als schillernde literarische Figur, deren Glaubwürdigkeit mit Hilfe der in unserem Analysedurchgang dargestellten erzähltechnischen Verfahren erzielt wurde, konnte die schöne Mulattin Cecilia zur symbolischen Verkörperung Kubas werden. ${ }^{72}$ Denn aus dem (von einander widersprechenden Diskursen geprägten) Bild der mulattischen Verführerin und Femme fatale konnte ein literarischer Mythos erstehen, der Bedingungen und Entwicklung von Transkulturation und nationalem Identitätsstreben - und dessen (vorläufiges) Scheitern auf Kuba - innerhalb eines Rahmens historischer Glaubwürdigkeit in einer einzigen weiblichen Figur verdichtet: Cecilia Valdés wurde zu einer Inkarnation Kubas.

Damit aber können wir der Frage nach den Aneignungen von Wirklichkeiten und deren romanesker Funktion in Hinblick auf Cecilia Valdés o La Loma del Ángel eine neue Dimension hinzugewinnen: Denn diese Aneignungen sind wie die erzähltechnische Strukturierung an der zentralen Funktion des Romanschaffens Cirilo Villaverdes orientiert. Schreibt sich Cecilia Valdés auch in die Reihe abolitionistischer kubanischer Romane von Gertrudis Gómez de Avellanedas Sab (1841) bis Anselmo Suárez y Romeros Francisco (1880) ein, so versteht Cirilo Villaverde sein literarisches Hauptwerk keineswegs - wie wir bereits konstatieren konnten vorrangig als Mittel direkter politischer Einflussnahme auf die Abschaffung der Sklaverei in Kuba. Denn Villaverde ging es trotz aller literarischen Orientierung seines Romans an spanischen Literaturmodellen vor allem um die Abschaffung des kolonialspanischen Gesellschafts- und Wirtschaftssystems. Durch die Interessenallianz zwischen Spanien und der einheimischen kreolischen Oligarchie war Kuba der Independencia unabhängig gewordener hispanoamerikanischer Staaten fern geblieben und ging damit im 19. Jahrhundert einen Sonderweg, der sich unter veränderten geopolitischen Vorzeichen auch in der zweiten Hälfte des 20. Jahrhunderts sowie in unserem 21. Jahrhundert im Zeichen der Kubanischen

72 Vgl. hierzu ausführlich Ette, Ottmar: Cirilo Villaverde: „Cecilia Valdés o La Loma del Ángel“. In: Roloff, Volker / Wentzlaff-Eggebert, Harald (Hg.): Der hispanoamerikanische Roman. Band 1: Von den Anfängen bis Carpentier. Darmstadt: Wissenschaftliche Buchgesellschaft 1992, S. 30-43, Anmerkungen S. 313-317. 
Revolution fortsetzt. Den von José Martí entfesselten Krieg von 1895 und den Zusammenbruch des spanischen Kolonialismus auf Kuba erlebte der 1894 verstorbene Villaverde nicht mehr.

Wir haben gesehen, dass Villaverde in seinem Romanschaffen das „delectare“ wahrlich nicht vergaß. Doch im Kern seines am „prodesse“ und einem pragmatisch zu erzielenden Nutzen orientierten Literaturbegriffs stand nicht das - wie er es nannte - „frivole“ Vergnügen am Erfundenen, sondern die ernsthafte Beschäftigung mit dem Erlebten und Nacherlebbaren. Einer Literatur im Dienste dessen, was Villaverde als gesellschaftlichen Fortschritt erachtete, waren damit all jene ästhetischen Strategien und Verfahren zugeordnet, die dem literarischen Artefakt die Glaubwürdigkeit und Authentizität des Historischen, ja Erlebten verliehen.

Aus diesem vorrangig didaktischen Zusammenhang heraus wird verständlich, warum Cirilo Villaverde seinem Lesepublikum besondere Aufmerksamkeit zuwandte und versuchte, eine dokumentarische, ja testimoniale, in jedem Falle tendenziell autobiographische Lesart seines Romans zu erzeugen. In diesen literarischen Strategien wie in seiner Literaturkonzeption insgesamt wird Aneignung von Wirklichkeit von der Seite des Autors wie von der Seite des Lesers zusammengedacht: in ihr verschmelzen Produktion und Rezeption. Zusammen erzeugen sie eine identitätsbildende politische, soziale und kulturelle Kraft, deren Ziel in Kuba eine Aneignung der gesellschaftlichen Wirklichkeit im vollen Wortsinne war. Es ist bezüglich der politisch-gesellschaftlichen Wirkkraft von Literatur faszinierend zu sehen, dass die von Villaverde intendierte Engführung von Geschichte, literarischer Fiktion und Leben die Figur einer schönen Mulattin entstehen ließ, in welcher sich die kubanische Gesellschaft auch und gerade seit ihrer Unabhängigkeit zu spiegeln vermochte. 